F. M. Cummings

June 1984

Prepared for the U.S. Department of Energy under Contract DE-AC06-76RLO 1830

Pacific Northwest Laboratory Operated for the U.S. Department of Energy by Battelle Memorial Institute

$\frac{\mathrm{PNL}-5136}{\mathrm{UC}-32}$

tons

\title{
TACI-A Code for Interactive Analysis of Neutron Data Produced by a Tissue Equivalent Proportional Counter
}

\author{
by Battelle Memorial institute
}




\title{
DISCLAIMER
}

This report was prepared as an account of work sponsored by an agency of the United States Government. Neither the United States Government nor any agency thereof, nor any of their employees, makes any warranty, express or implied, or assumes any legal liability or responsibility for the accuracy, completeness, or usefulness of any information, apparatus, product, or process disclosed, or represents that its use would not infringe privately owned rights. Reference herein tn any specific commercial product, process, or service by trade name, trademark, manufacturer, or otherwise, does not necessarily constitute or imply its endorsement, recommendation, or favoring by the United States Government or any agency thereof. The views and opinions of authors expressed herein do not necessarily state or reflect those of the United States Government or any agency thereof.

\author{
PACIFIC NORTHWEST LABORATORY \\ operated by \\ BATTELLE \\ for the \\ UNITED STATES DEPARTMENT OF ENERGY \\ under Contract DE-AC06-76RLO 1830
}

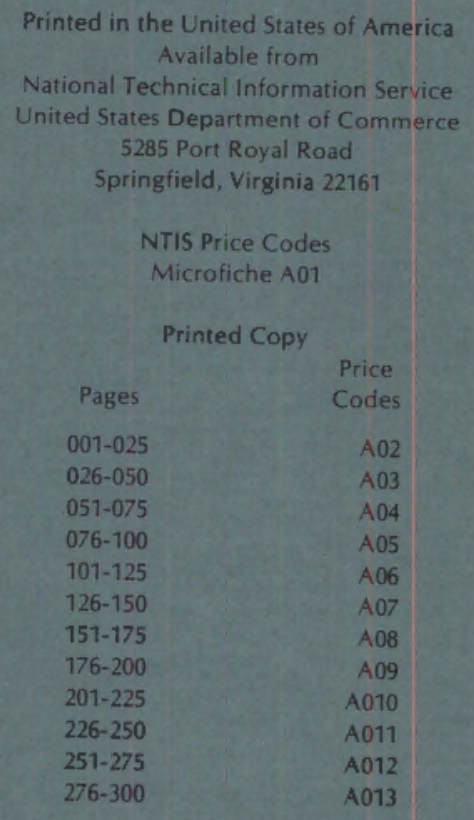


TACI - A CODE FOR INTERACTIVE ANALYSIS

OF NEUTRON DATA PRODUCED BY A TISSUE

EQUIVALENT PROPORTIONAL COUNTER

F. M. Cummings

June 1984

Prepared for the U.S. Department of Energy under Contract DE-AC06-76RLO 1830

Pacific Northwest Laboratory Richland, Washington 99352 


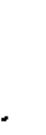

. 
CONTENTS

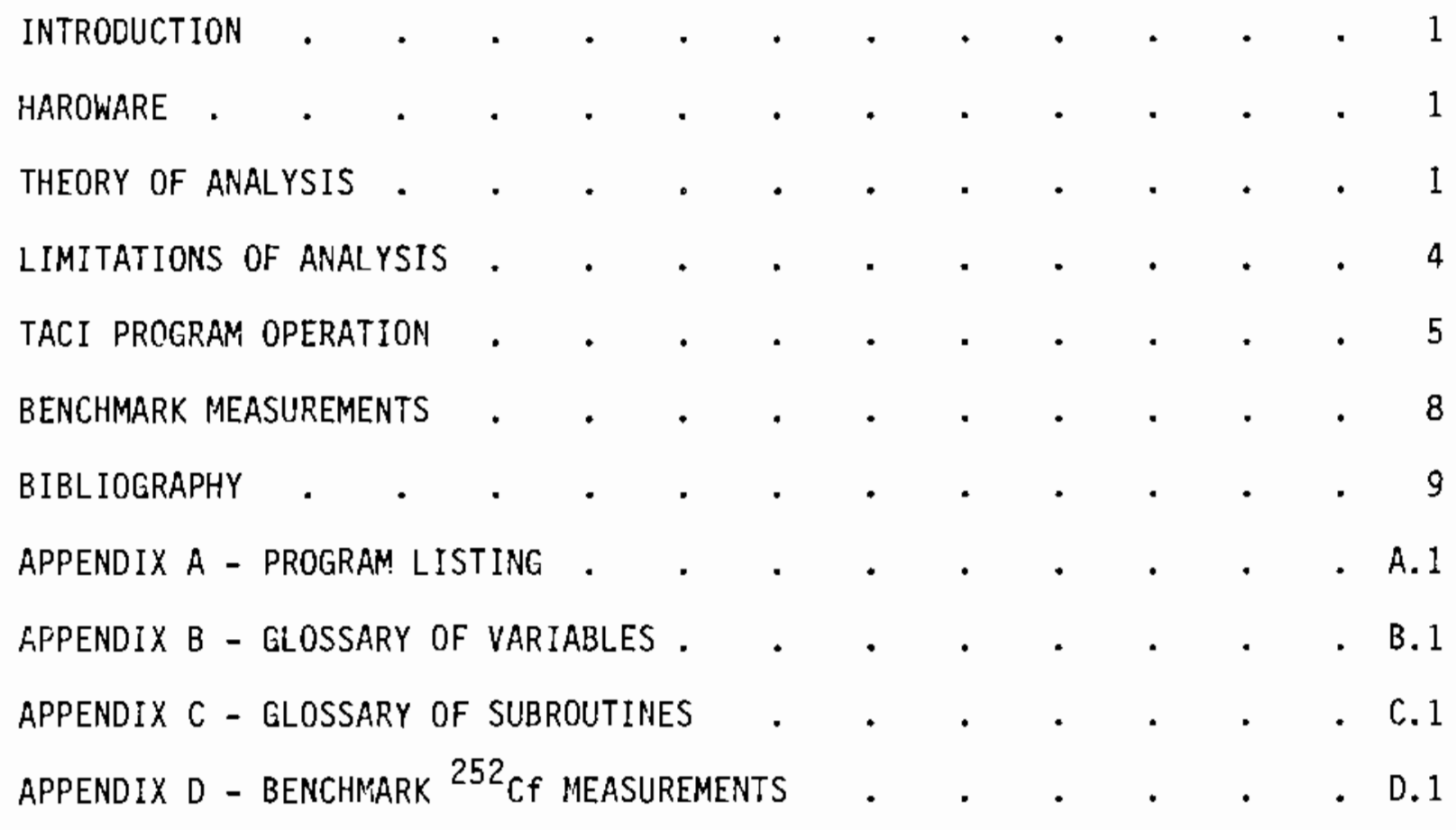




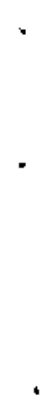


TACI - A CODE FOR INTERACTIVE ANALYSIS OF NEUTRON DATA

PRODUCED BY A TISSUE EQUIVALENT PROPORTIONAL COUNTER

INTRODUCTION

The TEPC analysis code (TACI) is a computer program designed to analyze pulse height data generated by a tissue equivalent proportional counter (TEPC). It is written in HP BASIC and is for use on an HP-87XM personal computer. The theory of TEPC analysis upon which this code is based is summarized by the International Commission on Radiological Protection (ICRP 1977).

HARCWARE

The hardware necessary to support this code include an HP-87XM personal computer, HP82901M Flexible Disc Drive, and the HP82905B Printer. An HP7470A $X-Y$ Plotter is an optional accessory.

In addition to the aforementioned hardware, the program requires an HP00087-15003 Rev A 1/0 Rom, an HP00087-15002 Rev A Plotter Rom, an HP0008715005 Rev A Advanced Programming Rom 1 and the HP00087-15005 Rev A Advanced Programming Rom 2. The Advanced Programming Roms may be omitted if the program is changed to determine the current date and time in another manner.

\section{THEORY OF ANALYSIS}

Neutrons interacting within the wall of a TEPC produce recoiling protons and heavier ions which travel through the TE filling gas depositing energy in the gas by ionization. The electronic pulses created by the passage of the charged recoil particle are collected at the counter anode, amplified and stored as a pulse height distribution in a multichannel analyzer. The energy deposited in the gas divided by the mass of the gas is the radiation dose which could be received by an equivalent volume of tissue in air as produced by neutrons. 
The TEPC is self-calibrating because the maximum amount of energy a proton can deposit in one micrometer of tissue (stopping power) is roughly $100 \mathrm{keV}$ (G1ass and Samsky 1967). The point at which that maximum occurs in each distribution will depend on the gain of the counting system, the gain of the analyzer and to a small part, the size of the equivalent tissue volume. That point is referred to as the proton drop point, or $p$-drop, and is found by locating the point of inflection in the distribution of proton events times the square of the pulse height, or channel [known as the $y \star D(y)$ distribution]. The data are smoothed by a digital filter and the 2nd derivative of $y * D(Y)$ is calculated pointwise by:

$$
d A(I)=\sum_{L=1}^{7} C(L) \times\left(\operatorname{CGS}(I+L) \times(I+L)^{2}-\operatorname{CTS}(I-L) \times(I-L)^{2}\right)
$$

where $\quad \mathrm{dA}(\mathrm{I})=2$ 2nd derivative at channei I

$$
\begin{aligned}
\operatorname{CTS}(\mathrm{I}+\mathrm{L}) & =\text { counts in channel } \mathrm{I}+\mathrm{L} \\
\mathrm{C}(\mathrm{L}) & =\text { weighting coefficients found in Table } 1 .
\end{aligned}
$$

TABLE 1. Digital Filter Weighting Coefficients

$\begin{array}{ll}C(1) & 0.01136 \\ C(2) & 0.02075 \\ C(3) & 0.02656 \\ C(4) & 0.02777 \\ C(5) & 0.02418 \\ c(6) & 0.01641 \\ c(7) & 0.00581\end{array}$

The $p$-drop is determined to be the minimum of the 2 nd derivative distribution between the proton recoil data and the heavy ion recoil data (refer to Figure 4). After the p-drop channet is determined, the values are calculated for the diameter and volume of an equivalent site size of tissue, the mass of the filling gas, the conversion of channel number to keV/micrometer and the conversion of counts times channel number to radiation dose. The maximum stopping power for protons is a slowly varying function of the tissue site size (Glass and Samsky 1967). The actual conversion for channet number to energy deposited per distance is interpolated from data in Glass and 
Samsky (1967). The dose is calculated using equation 3.1-11 in ICRV (1977) and adjusted to account for site size.

The $y^{\star} D(y)$ distribution highlights the region where the events from proton recoils overlap the events from the electron recoils. Where there is sufficient data to find the minimum in the $y * D(y)$ distribution between these two regions, then the start of neutron data is taken to be that minimum (refer to Figure 6). That is, events more energetic than the neutron start point are considered to be due to proton recoils entirely and the events less energetic than the neutron start point are considered to be due to electron recoils entirely. If there are not enough data from electron recoils to determine that point, a default value of $7 \mathrm{keV} / \mathrm{micrometer}$ may be used (empiricalizy determined from ${ }^{252} \mathrm{Cf}$ irradiations). Variations of a few channels around the actual neutron start channel will not contribute significant error to the measurement.

Integral doses are calculated by the following equations:

$$
\begin{aligned}
D_{\text {gamma }} & =\operatorname{RADFAC} \times \sum_{I=G S}^{N S T-1} \operatorname{CTS}(I) \times I \\
D_{\text {neutron }} & =\operatorname{RADFAC} \times \sum_{I=N S T}^{N C} \operatorname{NS}(I) \times I
\end{aligned}
$$

where $\quad D_{\text {gamma }}=$ absorbed dose due to gamma-induced events, mrad

$D_{\text {neutron }}=$ absorbed dose due to neutron-induced events, mrad

RADFAC $=$ conversion factor

GS = first non-zero channel number

NST = neutron start channel

$\mathrm{NC}=$ total number of channels.

The integral dose equivalents are calculated by assuming that the average LET for a given channel number is equal to $4 / 3$ the lineal energy equivalent to that channel. (The factor $4 / 3$ comes from (1) the average linea 1 energy = average energy deposited divided by the mean chord length of the chamber, or, $y=E /(2 / 3 \star D)$ and (2) the average LET is related to the average $y$ at a channe? 
by $L=8 / 9 y$ so that $L=8 / 9 y=8 / 9 \times 3 / 2 \times E / D$.) The quality factor is related to the average $L$ by equation (4) which is a solution of the quality factor curve in ICRP 21, Figure 2.

$$
\begin{aligned}
& y<=3.5 \mathrm{keV} / \text { micrometer } Q(\mathrm{y})=1 \\
& 3.5>y<=175 \mathrm{keV} / \text { micrometer } Q(y)=-7.1680+13.4095 \times \ln (y)-7.7259 x \\
& \ln (y)^{\wedge} 2+1.9651 \times \ln (y) \wedge 3-0.1500 x \\
& \ln (y) \bullet 4 \\
& y>=175 \mathrm{keV} / \text { micrometer } Q(\mathrm{y})=20 \\
& \text { where } \quad y=4 / 3 \times \text { I } \times \text { KEVCH } \\
& \mathrm{KEVCH}=\text { conversion of channel to } 1 \text { ineal energy }
\end{aligned}
$$

The dose equivalents for ganma and neutron events are calculated by equations 5 and 6 below:

$$
\begin{aligned}
& \text { gamma }=\operatorname{RADFAC} \times \sum_{I=G S}^{N S T-1} \operatorname{CTS}(I) \times I \times Q(y) \\
& \text { neutron }=\text { RADFAC } \times \sum_{I=N S T}^{N C} C T S(I) \times I \times Q(y)
\end{aligned}
$$

where gamma $=$ the gamma dose equivalent, mrem

$$
\begin{aligned}
\text { neutron } & =\text { the neutron dose equivalent, mrem } \\
Q(y) & =\text { quality factor for Iineal energy of ' } y \text { ' }
\end{aligned}
$$

\section{LIMITATIONS OF ANALYSIS}

There are several limitations on this kind of measurement relating to the assumptions about the slowing down of recoils in the counter, the actual effect of energy straggling and the relationship of the dose from heavy recoils versus the dose from neutron-induced gamma events. Nonetheless, the measurement seems to be sufficiently accurate for occupational dose and dose rate measurements and the determination of neutron dose and dose equivalent.

Limitations imposed on the results by the calculation technique include the following: 
(1) NSTART - the neutron start point is chosen such that the overlapping portions of the $y * D(y)$ distribution between the electron recoil and proton recoil regions are essentialiy equal. While that situation wil no generaily be strictly true, the error introduced by the assumption is small (on the order of $2 \%$ ).

(2) LET $=8 / 9 \mathrm{y}$ - this assumption is enumerated in depth in Borak and Stinchcomb, 1982. It is a good approximation for equivalent site diameters of 2 micrometers or less (on the order of $5 \%$ ).

(3) W factor - it is assumed that the energy necessary to create ion pairs in TE gas will be slowly varying and an average value will suffice for the accuracy of measurement (on the order of $1 \%$ ).

\section{TACI PROGRAM OPERATION}

During this section, refer to Appendix A for line by line listing of the code.

DATA INPUT lines $20: 360$

Prior to data input, if the computer senses a date of 0 then the operator is queried for the correct date by:

'Enter today's date (MM/DD/YYYY)...'

The operator responds by entering the correct date, e.g. 03/23/1984.

The operator is then queried for the correct time by:

'Enter the current time (HH:MM:SS)...'

The operator responds by entering the current time, e.g. 09:27:30.

The internal clock is set and the operator is directed to load a 5-1/4-in. floppy disc which contains the input data on drive 1 of the HP disc drive. The disc is cataloged to display the avaitable input files. The program expects input files which are constructed serially containing (1) the total number of data channels, (2) the run title (80 characters-alpha), and (3) data (see Figure 1). The first two data channels contain the live time and real time, respectively. The operator enters the name of the input file. 
PARAMETER INITIALIZATION lines $370: 590$

Ouring this section of the program, the operator must indicate or enter the physical parameters of the measurement, i.e., the type of filing gas (Figure 2), the temperature of the gas at the time the counter was filled (Figure 3), the gas filling pressure, the gas density and the diameter of the counter. Default values for the gas temperature and counter diameter are $25^{\circ} \mathrm{C}$ and $12.7 \mathrm{~cm}$ respectively. The default values for pressure and density for propane-based TE gas are 7.2 torr and $0.001820 \mathrm{~g} / \mathrm{cc}$ respectively and for methane-based TE gas: 13 torr and $0.001136 \mathrm{~g} / \mathrm{cc}$ respectively.

2nd OERIVATIVE CALCULATION lines 600:830

The first calculation in this portion of the code adjusts the gas density to account for temperature and pressure variations. The initial channel for the 2nd derivative calculation is referred to as the KNEE and is determined by setting it as shown:

if $N C>1100$ and $\mathrm{KNEE}=0$ then $\mathrm{KNEE}=\mathrm{INT}(\mathrm{NC} / 20)$

$N C<=1100$ and $\mathrm{KNEE}=0$ then $\mathrm{KNEE}=\mathrm{MIN}(\mathrm{NC} / 5,100)$

This is done because the p-drop is assumed to be between channel 100 and 400 for most cases where $N C=2048$ and between 100 and 300 where $N C s=1024$.

The upper boundary of the loop for calculating the 2 nd derivative is set as shown below:

$$
\text { if } \begin{aligned}
\mathrm{NC} & >1100 \text { then } \mathrm{ANKL}=\mathrm{INT}(\mathrm{NC} / 5) \\
\mathrm{NC} & <1100 \text { then } \mathrm{ANKL}=\operatorname{MAX}(\mathrm{NC} / 2.300)
\end{aligned}
$$

The 2nd derivative distributions is calculated for this range of channels and then plotted. The operator has the option of recalculating the distribution by introducing new loop boundaries. Figure 4 is a plot of a typical neutron run.

\section{P-DROP DETERMINATION ] ines 840:1130}

The p-drop is determined by finding the minimum in the 2nd derivative distribution. The operator is then allowed to verify the point by viewing the plot, entering new plot boundaries (KNEE and ANKL), entering a value of p-drop or entering the channel corresponding to the alpha peak (Figure 5). At this 
time the relationship between the alpha peak and the proton drop point for methane-based TE gas at 2 micrometers equivalent has been established empirically to be: $P D P=.92 \times$ Alpha channel. The same relationship is assumed for propane, but the value could be different.

TISSUE PARAMETER CALCULATION 1 ines $1140: 1230$

The equivalent site size, gas mass and conversion factors are calculated using this section. The actual calculations are enumerated below:

$$
\begin{aligned}
\text { EQDIA } & =10000 \times \text { DIA } \times \text { RHO } \\
\text { MASS } & =0.5236 \times D^{\wedge} 3 \times \text { RHO } \\
\text { RADFAC } & =1.602 \times 10^{\wedge}(-11) \times \text { KEVCH/MASS } \times 1000 \times \text { EQDIA } \\
K E V C H & =\text { RKEVM } / P D P
\end{aligned}
$$

where $\quad$ EQDIA $=$ diameter of an equivalent volume of tissue, micrometers MASS = mass of the filling gas, grams

RADFAC $=$ dose conversion factor from ICRU 1977, equation 3.1-11

$\mathrm{KEVCH}=$ converts channel to 1 ineal energy, $\mathrm{keV} / \mathrm{micrometer} / \mathrm{channe}]$

RKEVM = value of maximum stopping power associated with the particular site size, $\mathrm{keV} / \mathrm{micrometer}$

$\mathrm{PDP}=$ channel in which the proton drop point occurs.

NSTART DETERMINATION LINES 1240: 1620

The neutron start point is calculated by locating the minimum in the $y \star D(y)$ distribution between the proton recoil region and the electron recoil region. If the neutron start point cannot be found between 5 and $15 \mathrm{keV} /$ micrometer then the $y^{\star} D(y)$ distribution is plotted for those channels between 3 and the one equivalent to $15 \mathrm{keV} /$ micron. The operator may then interactiveiy select the neutron start point by moving a cursor on the plot, selecting a new range of investigation, by selecting a default value corresponding to $7 \mathrm{keV} /$ micrometer or by entering a neutron start channel.

DOSE AND DOSE EQUIVALENT OETERMINATION lines 1630:1990

The neutron absorbed doses and dose equivalents are calculated as shown in earlier equations. The associated rates are determined by dividing by the 
live time of the measurement. Additional distributional parameters are calculated including: number of counts associated with the neutron and gamma portions of the raw data distribution, the number of events of channel number times counts and the integral values in the $y^{\star} D(y)$ distribution. From these parameters are calculated the average lineal energies in the frequency and dose distributions and the average linear energy transfer in the dose distribution.

TEPC OUTPUT SUMMARY I ines 2000:2410

The data and associated parameters are printed out to the HP Printer and the CRT as shown in Figure 6 .

PLOTTING Tines 2420:2460

The operator may indicate the necessity of plotting (Figure 7) the different distributions. The plotter must be identified (Figure 8) and the type of plot must also be indicated (Figure 9). The actual plotting is performed in a plotting subroutine contained in 1 ines $3770: 412 \mathrm{D}$ and in 1 ines 2720:3610. Examples of input data plots produced on the CRT and on the HF plotter are presented in Figures 10 and 11 for inspection.

PRINT INPUT DATA lines 2470:2510

The operator is given the opportunity to print the input data on the HP printer (an example of the printout is given in Figure 12). The actual print subroutine is contained in lines $4130: 4350$.

ADDITIONAL ANALYSES lines 2520:2560

The operator is given the opportunity to perform additional analyses using the same parameters as the previous analysis (Figure 13). The advantage of performing multiple analyses is chiefly that the run time is reduced by narrowing the window used to calculate the 2 nd derivative distribution.

\section{BENCHMARK MEASUREMENTS}

During March 1983, benchmark measurements were performed at the NBS californium-252 irradiation facility using a 5-in. TEPC to test the acceptability of the analysis code. Previous measurements have been performed and 
are in good agreement, but not documented at this time. The TEPC was placed $56.36 \mathrm{~cm}$ from the center of the $0_{2} 0$-moderated ${ }^{252} \mathrm{Cf}$ source in the low scatter facility. The emission rate of the source was $8.91 \mathrm{E} 8 \mathrm{n} / \mathrm{s}$ and the dose equivalent rate at $56.35 \mathrm{~cm}$ was calculated by using equation 1 in NUREG/CR-2957 (McDonald et al. 1983). The equation was modified by a factor of 0.89 because $11 \%$ of the emitted neutrons are below the cadmium cut-off energy $(0.5 \mathrm{eV})$ and the cask containing the $\mathrm{D}_{2} 0$ and ${ }^{252} \mathrm{Cf}$ source includes a spherical $0.5-m \mathrm{~m}$ cadmium shell (Schwartz and Eisenhauer 1980). The calculated dose equivalent rate was $645 \mathrm{mrem} / \mathrm{hr}$ at $56.35 \mathrm{~cm}$. The TEPC output summary is contained in Appendix $\mathrm{D}$ along with pertinent plots. The dose equivalent rate determined using the TEPC was $637 \mathrm{mrem} / \mathrm{hr} \pm 37 \mathrm{mrem} / \mathrm{hr}$ (1 standard deviation). The benchmark measurement is included in the document for quality assurance purposes.

\section{BIBLIOGRAPHY}

Borak, T. B., and T. G. Stinchcomb. 1982. "Errors in Estimating Neutron Quality Factor Using Lineal Energy Distributions Measured in TissueEquivalent Proportional Counters." Health Phys. 43(2):219.

Glass, W. A., and D. N. Samsky. 1967. "Ionization in Thin Tissue-Like Gas Layers by Monoenergetic Protons." Radiation Research 32, 138.

Hewlett-Packard HP-87. Operating and BASIC Programming Manual.

Hewlett-Packard. Advanced Programming ROM Owner's Manual.

International Comrnission on Radiological Protection (ICRP). 1971. Data for Protection Against Ionizing Radiation From External Sources: Supp Tement to ICRP Publication 15. ICRP Publication 21, Pergamon Press, 0xford.

McDonald, J. C., R. V. Griffith, P. PTato, J. Miklos. 1983. Measurements of Gamma-Ray Dose from a Moderated ${ }^{252} \mathrm{Cf}$ Source. NUREG-2957, Nuclear Regulatory Commission, Washington, 0.C.

Schwartz, R. B., and C. M. Eisenhauer. 1980. The Design and Construction of a $\mathrm{D}_{2} 0$-Moderated ${ }^{252} \mathrm{Cf}$ Source for Calibrating Neutron Personnel Dosimeters Used at Nuclear Power Reactors. NUREG/CR-1204, NucTear Regulatory Cominission, Washington, D.C. 


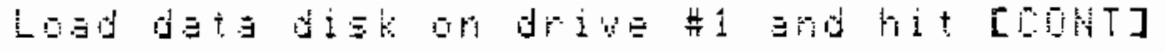

[ Volu解 ]: CLEAH

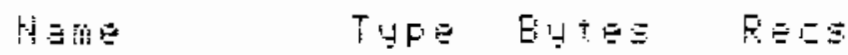

THPIO DATA $25 E$ ES

TL1 DATA 256 S5

TH1 DHTA 258 ES

TLE DATH Z5E G5

THE DATA 250 ES

TLS DATH 250 ES

THO QRTH $25 E$ OS

TOOHH DETA $25 E$ ES

TCOHL LETH $25 E$ BE

TFLOT FEUE ZE 12

bhat is the name of the input data file, .

FIGURE 1. 
File: rittit

Low Gain neutron gFectrum from moderated-Cf 11/18/83 (LRE\# 5358-fo2e)

Fropine or Methane?

•

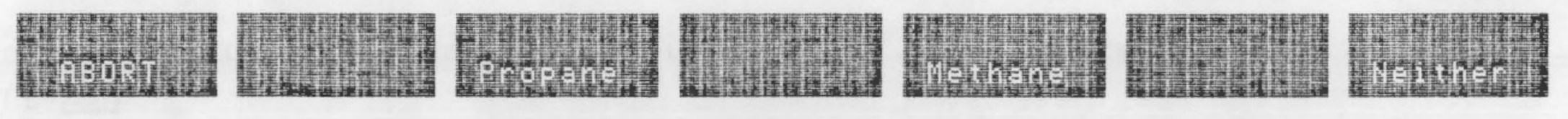

FIGURE 2. 


\section{FILE: IIT}

Low Gain neutron sfectruli from moderated-Cf $11 / 18 / 83$ (LRE\# 5358-Fg22)

$$
\text { GAS = FROPAHE }
$$
Gas Tenferature
Gas Fressure
(torr)
Gas Density
(g/ce)
Counter Dianeter.
c

7,2

. 001820

12.7

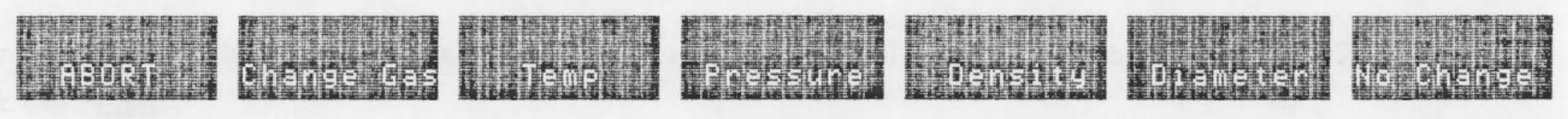

FIGURE 3. 
Low Gain neutron spectrum from moderated-Cf $11 / 18 / 85$ (LRE\# 5358-pg22) INFUT FILE NAME: TL 1

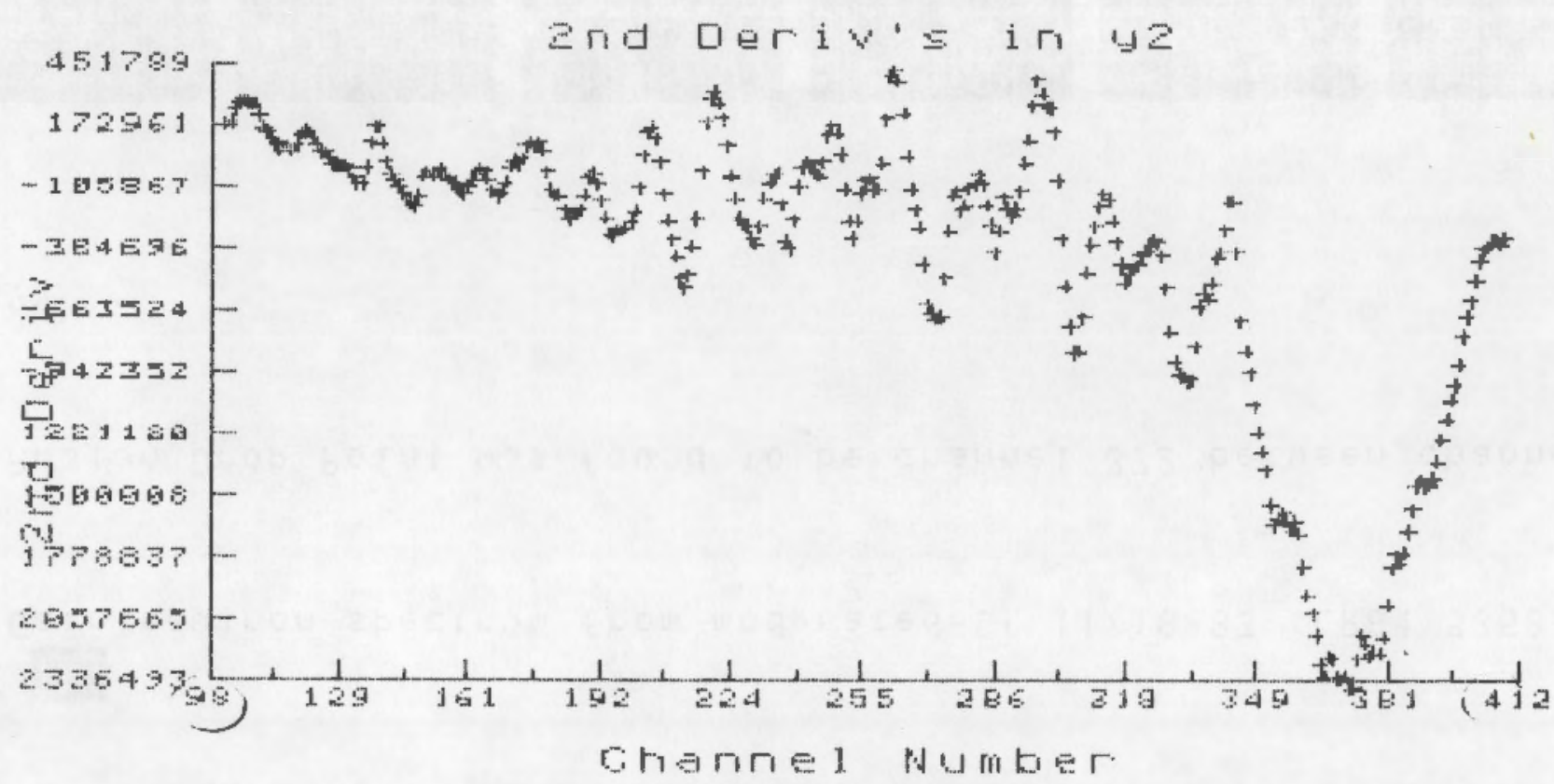

FIGURE 4. 


\section{F I LE: IIIIII}

Low Gain neutron zpectrum from lioderated-cf 11 / 18 /83 (LRE\# 5358-pg22)

The Froton orof Foint was found to be channel 372 between channels 1 a 2409

$\stackrel{\rightleftarrows}{\not}$ Okay??

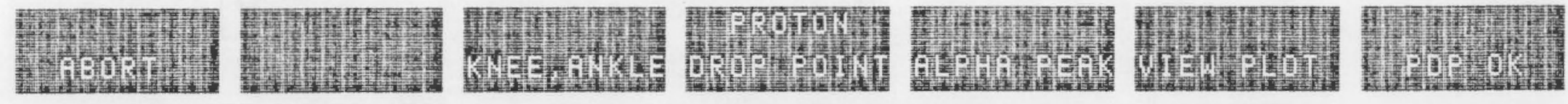

FIGURE 5. 
Low Gain neutron spectrum from moderated-Cf $11 / 18 / 83$ (LFB\# 535B-pg22) INPUT FILE NAME: TL1

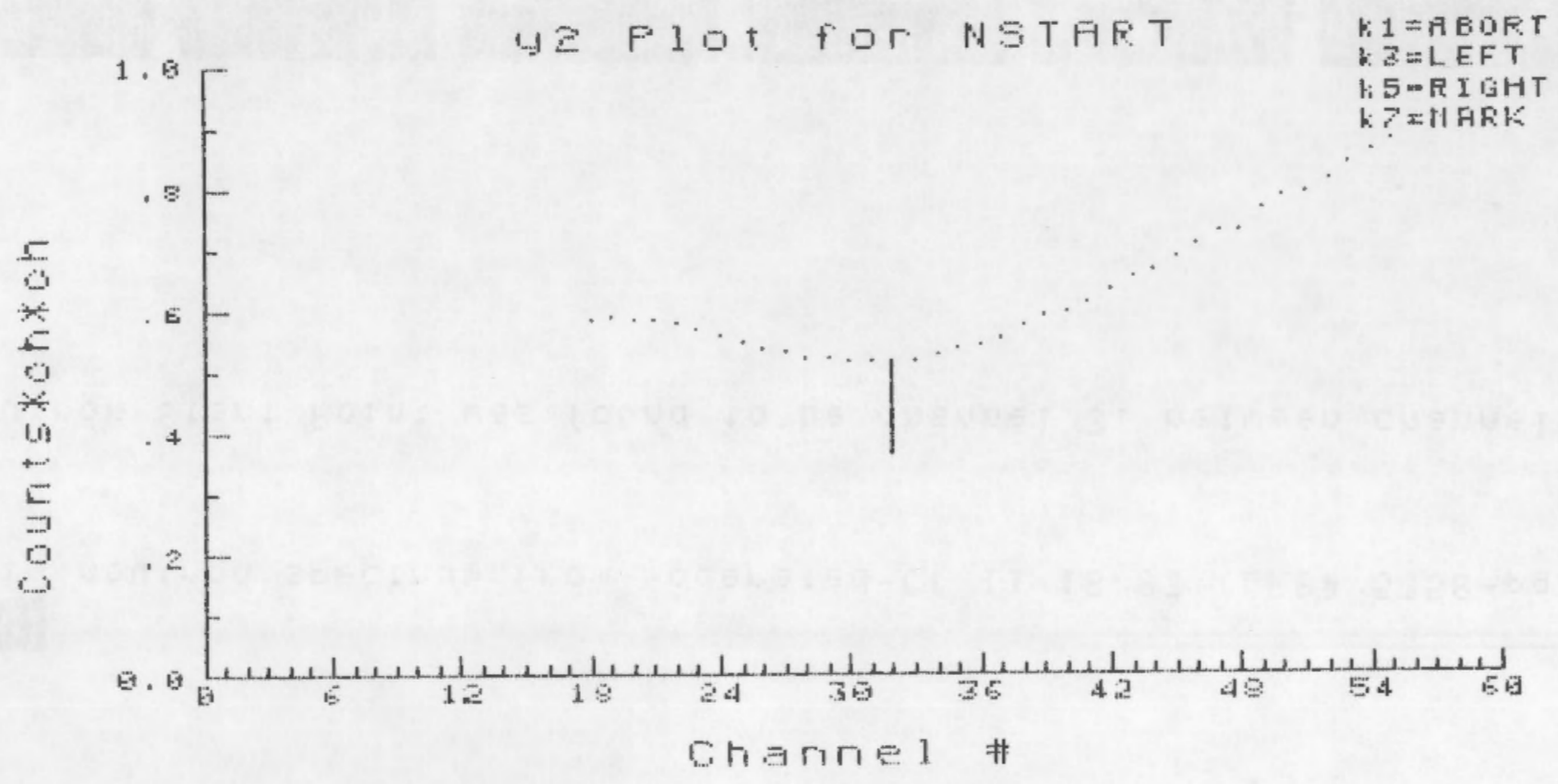

FIGURE 6. 


\section{FILE: 黛}

Lou Gain neutron gFectruli from moderated-cf $11 / 18 / 83$ (LRE\# 5358-pg22)

The Neutron start Foint was found to be channel 31 between channela 18 a 55

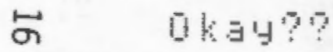

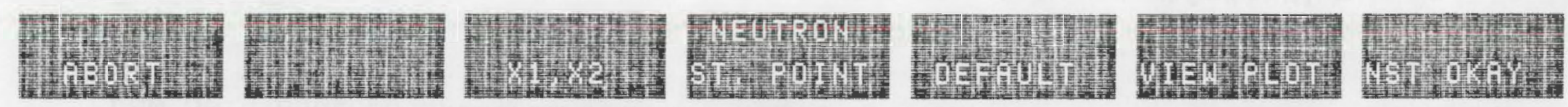

FIGURE 7. 


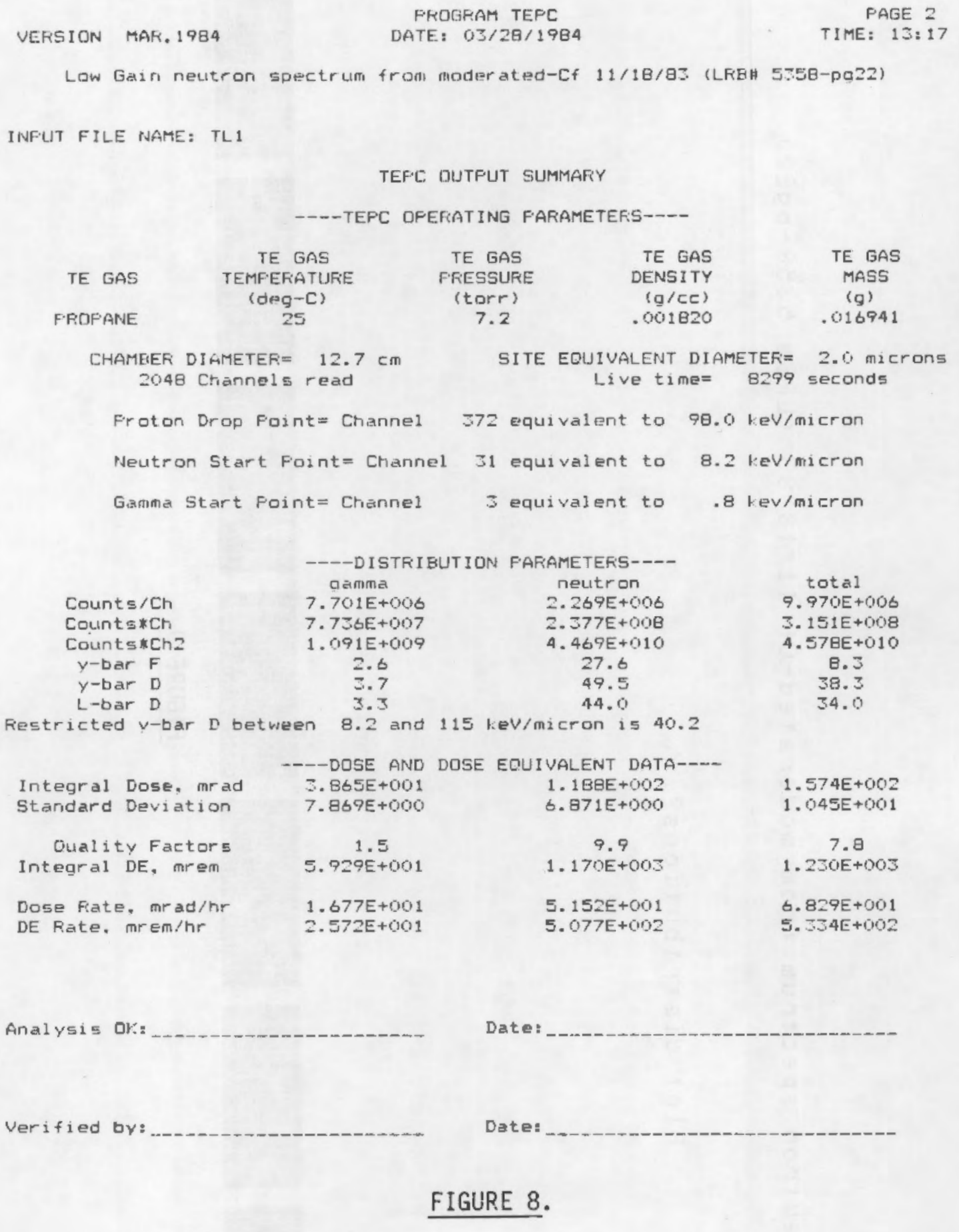




\section{FILE : 隽整}

Low Gain neutron gfectrum from moderated-Cf $11 / 18 / 83$ (LRE\# 5358-Fg22)

\section{Plot distributions?...}




\section{FILE: THIT}

Low Gain neutron spectrun froli moderated-Cf 11/18/83 (LRE\# 5358-pg22)

HF Plotter or CRT?...

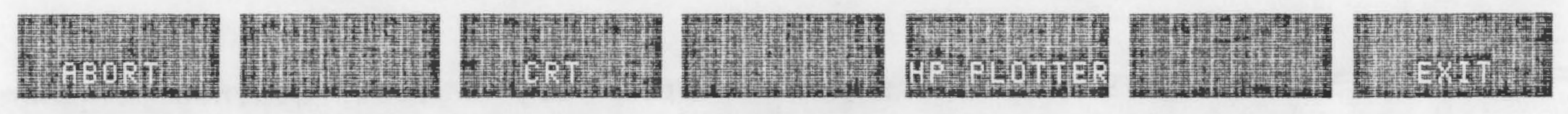

FIGURE 10. 


\title{
FILE: 笽
}

Low Gain neutron gpectrufi from moderated-Cf $11 / 18 / 83$ (LRE\# 5358-Fg22)

\author{
Flease gelect type of plot,
}

ธ

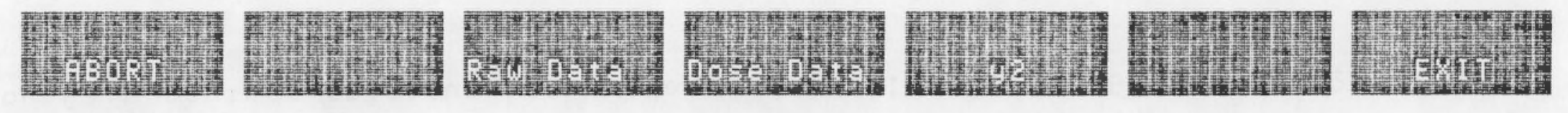

FIGURE 11. 
Low Gain neutron spectrum from moderated INFUT FILE NAME: TL1

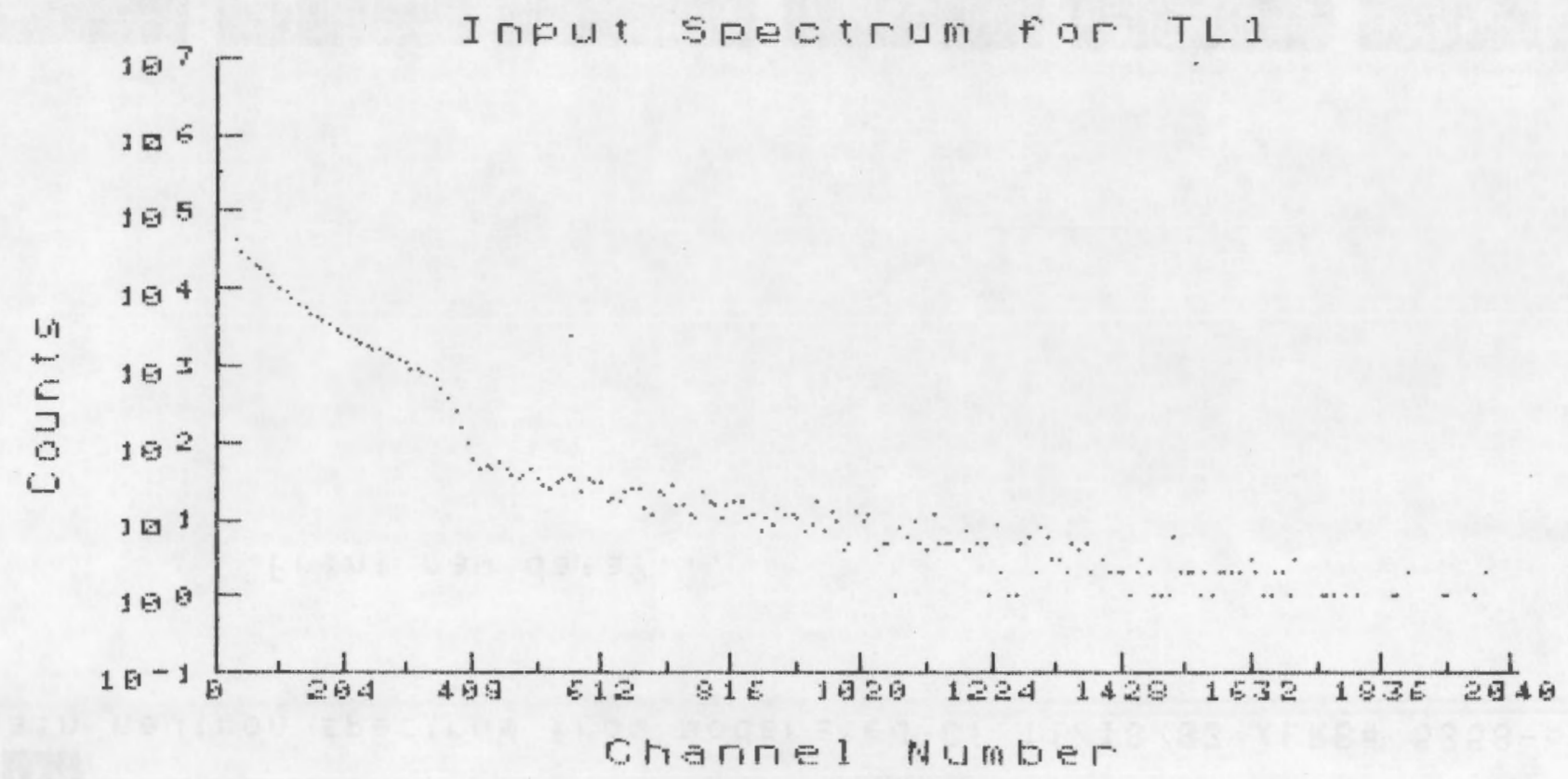

FIGURE 12. 


\section{FILE: :}

Low Gain neutron spectruf from fioderated-cf 11/18/83 (LRB\# $5358-F 922$ )

$$
\text { Print raw data? . . }
$$

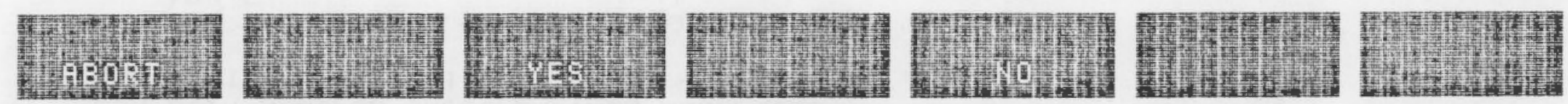

FIGURE 13. 


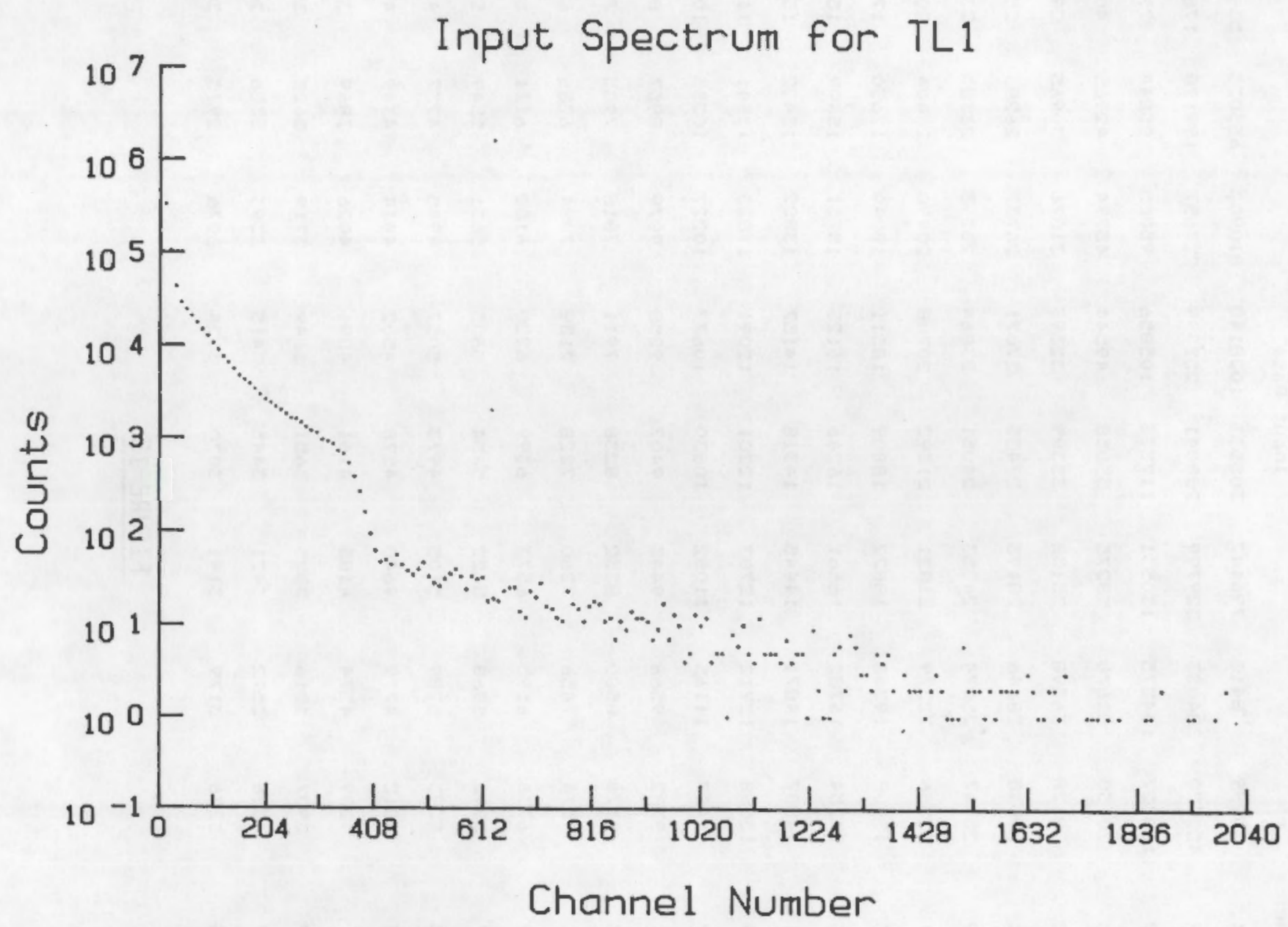

FIGURE 14. 
TEPC Input Data from file: TL1 $03 / 22 / 1984$

FAGE 2

Low Gain neutron spectrum from moderated-Cf $11 / 18 / 83$ (LRE* 535E-pg22)

\begin{tabular}{|c|c|c|c|c|c|c|c|c|}
\hline Channel & & & & Input & Data & & & \\
\hline 1 & 8299 & 8413 & 796147 & 305533 & 1029148 & 810903 & 655033 & 539420 \\
\hline 9 & 452320 & 384023 & 329799 & 288041 & 252399 & 223657 & 199178 & 178236 \\
\hline 17 & 160527 & 144375 & 130531 & 117333 & 105856 & 95885 & 85844 & 77565 \\
\hline 25 & 70130 & 63678 & 58275 & 53058 & 49544 & 45794 & 42965 & 40430 \\
\hline 33 & 38128 & 36396 & 35138 & 33389 & 32393 & 31876 & 30965 & 29797 \\
\hline 41 & 29038 & 28646 & 28193 & 27435 & 27071 & 26732 & 26283 & 25238 \\
\hline 49 & 25447 & 25074 & 24353 & 24051 & 23864 & 23593 & 23193 & 23006 \\
\hline 57 & 22566 & 22279 & 21821 & 21392 & 20708 & 20490 & 20404 & 20073 \\
\hline 65 & 19908 & 19368 & 18922 & 18809 & 18511 & 18040 & 17630 & 17567 \\
\hline 73 & 17254 & 16782 & 16661 & 16246 & 16123 & 15751 & 15409 & 15176 \\
\hline 81 & 14887 & 14871 & 14445 & 14318 & 14157 & 13822 & 13422 & 13212 \\
\hline 89 & 13008 & 12712 & 12703 & 12201 & 12091 & 11823 & 11941 & 11453 \\
\hline 97 & 11437 & 11165 & 11052 & 10630 & 10677 & 10227 & 10255 & 10065 \\
\hline 105 & 9792 & 9566 & 9443 & 9407 & 9258 & 9079 & 8957 & 8845 \\
\hline 113 & 8576 & 8500 & 8352 & 8238 & 7911 & 7818 & 7935 & 7769 \\
\hline 121 & 7574 & 7456 & 7260 & 7228 & 7189 & 7084 & 6786 & 6818 \\
\hline 129 & 6736 & 6595 & 6573 & 6399 & 6220 & 6180 & 6111 & 6092 \\
\hline 137 & 5992 & 5868 & 5622 & 5654 & 5605 & 5631 & 5549 & 5537 \\
\hline 145 & 5283 & 5289 & 5105 & 4973 & 5057 & 4945 & 4737 & 4871 \\
\hline 153 & 4812 & 4779 & 4640 & 4578 & 4502 & 4414 & 4349 & 4312 \\
\hline 161 & 4289 & 4274 & 4183 & 4161 & 4091 & 4026 & 3869 & 3944 \\
\hline 169 & 3907 & 3816 & 3883 & 3651 & 3649 & 3719 & 3622 & 3514 \\
\hline 177 & 3536 & 3572 & 3421 & 3445 & 3415 & 3393 & 3386 & 3179 \\
\hline 185 & 3276 & 3179 & 3141 & 3070 & 3124 & 3076 & 2973 & 3003 \\
\hline
\end{tabular}

FIGURE 15. 


\title{
F ILE: TIII
}

Low Gain neutron Epectrunil from linoderated-Cf $11 / 18 / 83$ (LRE\# 5358-pg22)

\author{
Finother TEFC run?...
}

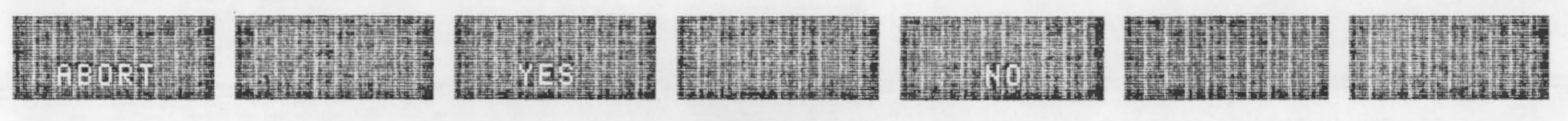

FIGURE 16. 

A.PPENDIX A

PROGRAM LISTING 
10 OFTION EASE 1

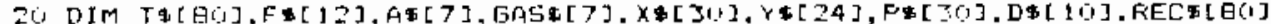

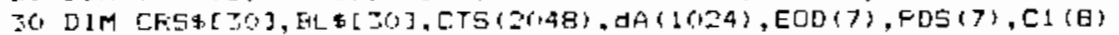

A1) DEF FNOF $(Y)=-7.161+1=.4095 * Y-7.7250 * Y^{\prime} Z+1.9651 * Y^{\prime} 3-15 * Y^{\prime} 4$

50 FFINTEFi IS 7011,80

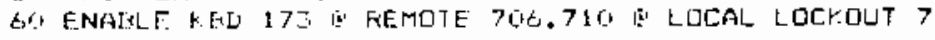

7 (1 GOSLIE INI

DO $F N=1$

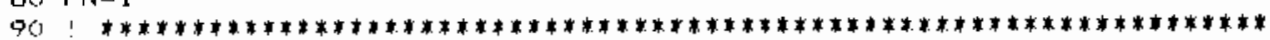

$100 !$ Read in data from disl.

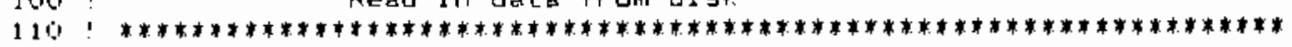

120 IF DATE $O$ THEN GOTO 180

130 CLEAF E DISF "Enter today'5 date (MM/DD/YYYY)..." E INFUT D\$

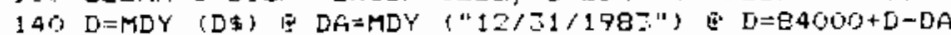

150 CLEAf I. DISF "Enter the current time (HH:MM:SS)..." g INFUT Ho

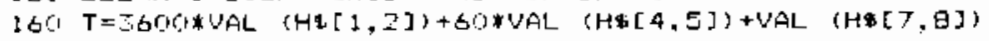

170 SETTIME T,D

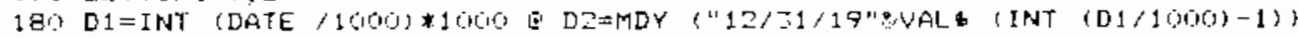

190 D\&FADY (DATE - D 1 +DZ)

20 IF KNEE\# THEN GOTO 230

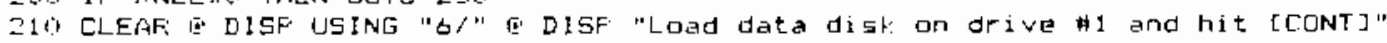

220 FAUSE

20 CAT "I D $701 "$

240 DISF. "What is the name of the imput data file..." E' INFUT T\&

750 T T=LEN (T\$)

2b0 F⿻[1

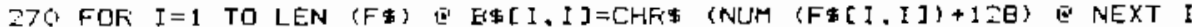

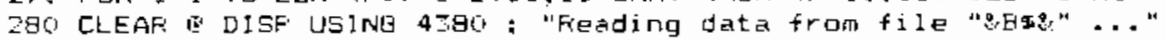

290 FEADH 1 ; $N C, T$ T

300 IF $\mathrm{NC}=204 \mathrm{Q}$ THEN READ 1 ; CTS()E EOTO 320

I10 FOR I $=1$ TO NC L' FEAD\# 1 a CTS (I) I. NEXT I

330 IF $K N E E=0$ THEN GOTD GAS

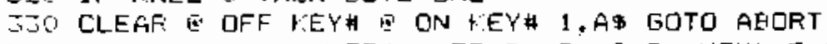

FAl ON REY\# " " YES" GOTO CALC İ DN KIEY\# 5," NO" GOTO GAS

ISG DISF USING 4410 ; "FILE: "En. T\$, "Same parameters as 1 act time?..."

IC)

$\$ 70$ GOTO $: 70$

క80

$\$ 90 !$ Enter counter parameters

$401, * * * * * * * * * * * * * * * * * * * * * * * * * * * * * * * * * * * * * * * * * * * * * * * * * * * * * * * * * * * * * * * * * * * * * * *$

410 GAS: CLEAF Ë OFF KEYY

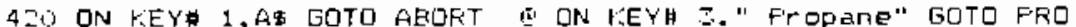

4:0 ON KEY\# E." Mettiane" GOTD MET Q ON KEY 7 ." Neither" GDTO NEI

440 DISF USING 4416 ; "File: "Eq,Tw. "Propane or Methane?" for LAEEL

450 GDTO 450

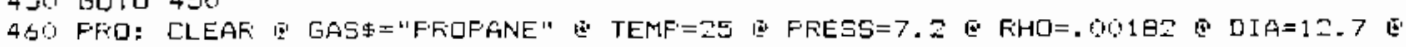
GOTO DIS

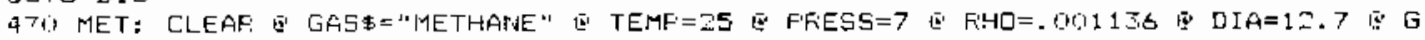

DTO DIS

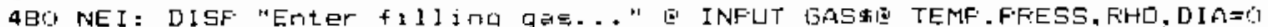

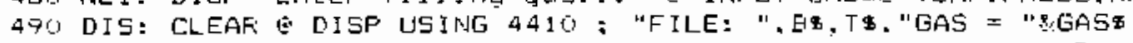

56 DISF" USING 4:90: "Gas Temper ature". "Bas Fressure" "Ges Densjty", "Counter Di arieter ", "c ", "(tarr)", "(a/ce)", "(cm)"

510 DISF IJSING 44 HO : TEMF, FFESS, FHO. DIA

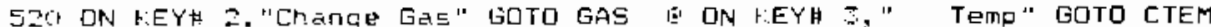

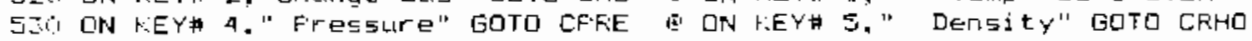

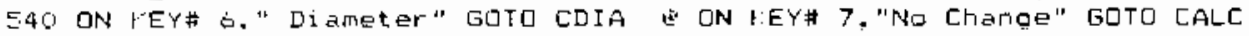

5ज) R.EY LAEEL

5ब GQTO 560 
576 C:TEM: DIGF "Gas Temper ature?..." IO INFUT TEMFI' BOTO DIS

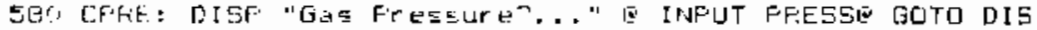

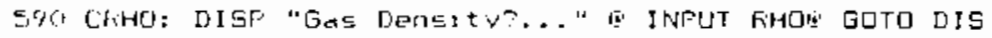

DGR, CDJA: DISF "Counter dameter?..." E' INFUT DIAË GOTO DIS

与l 1 !

626! Calculate Zrid derlvatives of $y$ C

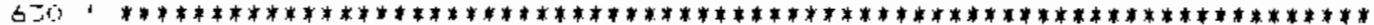

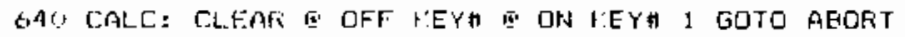

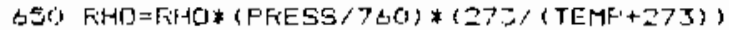

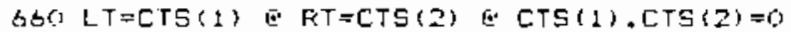

670 IF NC 1101 THEN HNEE=MIN (NC/5.100) O' ANKL =MAX (NC/2, 300)

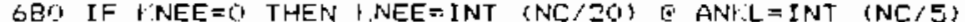

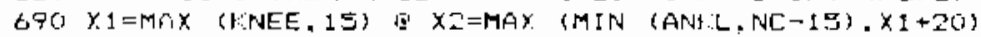

7orl DISF USING 4410 ; "File:" B\$.T\$."Calculating 2nd derivatsves..."

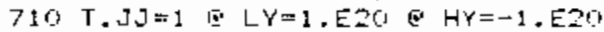

72, FOFi $I=X I$ TO $X Z$

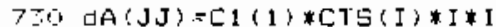

740 FOF: $L=2$ TO $\mathrm{B}$

$7 G(1) d A(J J)=d A(. J J)+C 1\{L) *(C 7 S(I+L) *(I+L) \cdot 2-C T S(I-L) *(I-L) \sim 2)$

$7 S C$ NEXT L

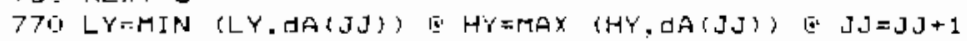

780 NEXT I

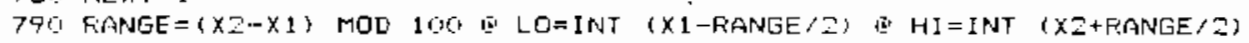

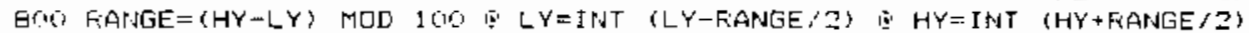

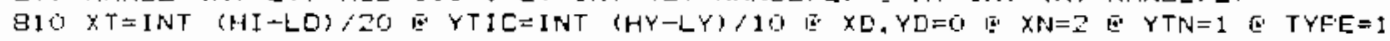

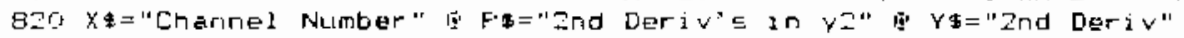

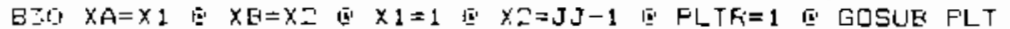

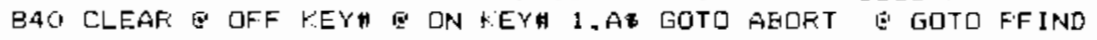

日50 $1 * * * * * * * * * * * * * * * * * * * * * * * * * * * * * * * * * * * * * * * * * * * * * * * * * * * * * * * * * * * * * * * * * * *$

Bscl ! Datermine Froton Drop Foint

B7o! The Fdrop is equivalent to the minimum in the Znd derivative curve of

8Q0 ! the $v * D(y)$ distribution....

穴

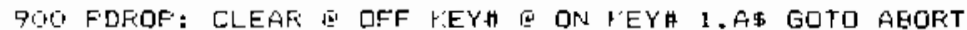

910 ON KEYH 3 , "KMEE, ANILE" GOTO FCAL. G ON KEYA 4, "DROP FOINT" GOTO FEIV

920 ON KEYH J." "ALFHA FEAY:" GQTO AGIV G' ON LEY\# \&. "VIEW FLOT" GOTD VIEW

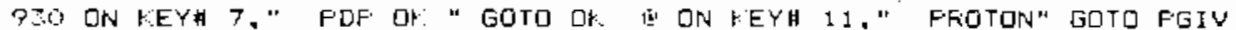

940 DISF USING 44Z0: "FILE: "E\$.T\$. "ThE Froton Drop Point was found to be chand El "UVAL (FDF) \&" between channels "QVAL\$ (KNEE)

85, $1:$ EY LAEEL

969 GOTO 960

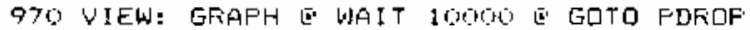

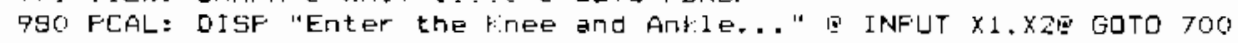

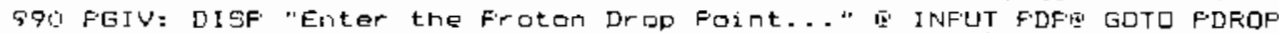

lory AGIV: DISF "Enter the Alpha Feat Channel..." I" IPFUT AL

1010 IF GAŞ中="METHANE" THEN FDF'=.92*AL E' GOTO FDFOF.

1020 , The relationship between the alpha peat and proton drop poipt was

1030 . deternined for inethane at 1 mcron equivaltent. The value for probare

$104 \%$ ! will be asstimed to be the same until verified experimentally...FMC

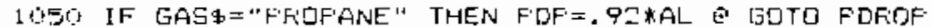

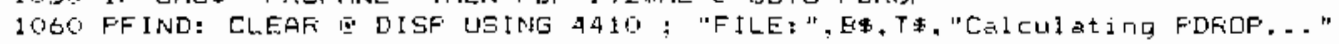

$1070 \mathrm{~T}=1$

1 OEO FOF $I=X 1$ TO $\times 2$

1690 IF $d A(I) \therefore=d A(T)$ THEN $T=I$

$110, N E X T$ I

$1110, F D F=X A-1+T$

1120 IF T\#XI AND T\#XI THEN GOTO FOFOF

1130 IF $T=X 1$ AND $X_{1} \div 15$ THEN $X 1=\operatorname{MAX}\left(15\right.$, INT $\left(X_{1-.2 * X 1)}\right)$ GOTO 710

1140 IF $T=x Z$ AND $X 2$ INC/Z THEN $X Z=M I N(N C-15$. INT $(X 2+.2 * \times 2)$ ) 60 GTO 710

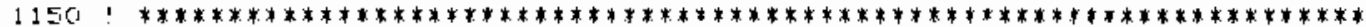




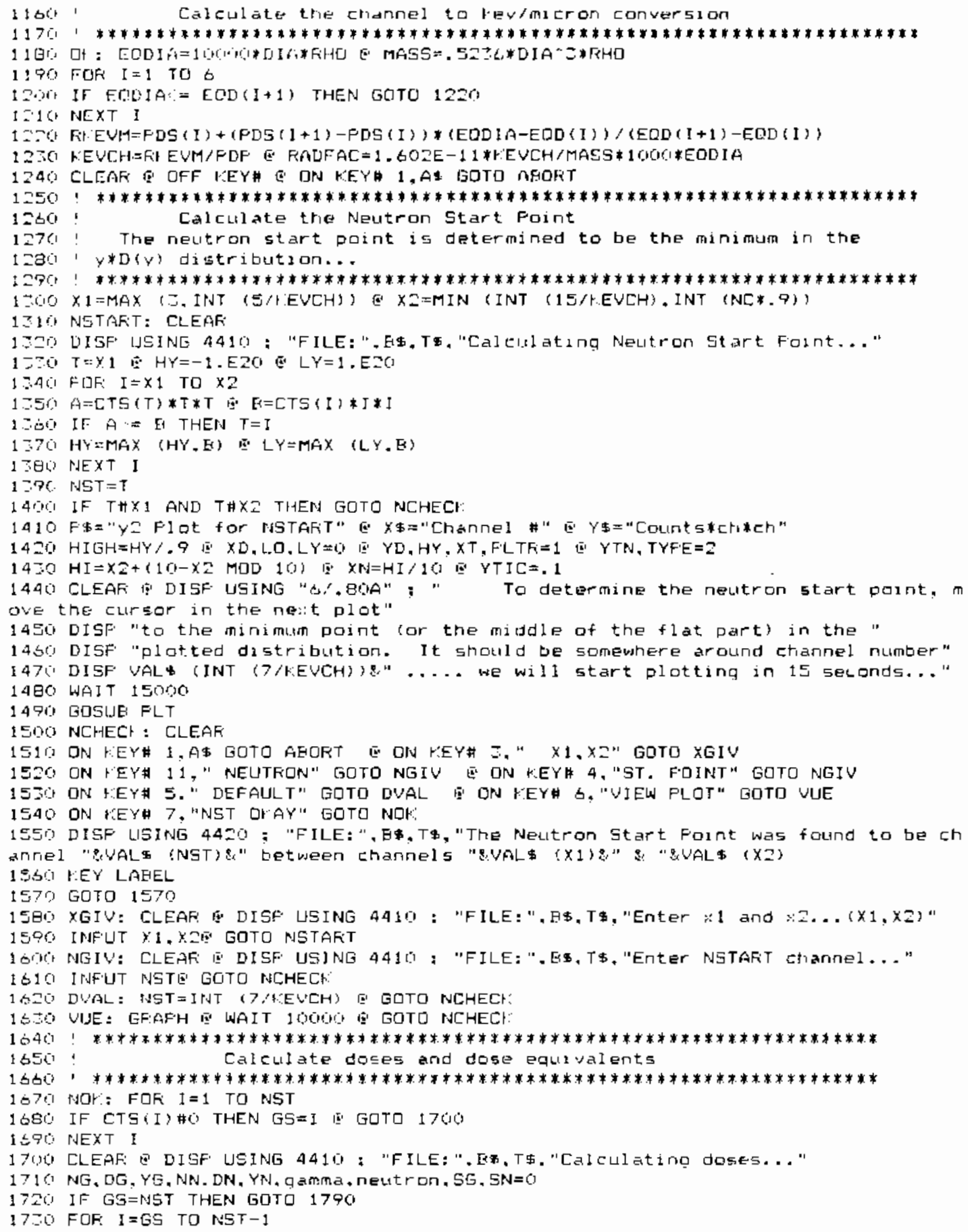




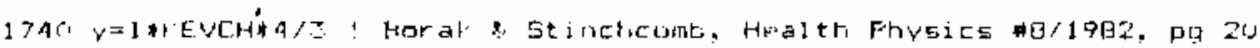

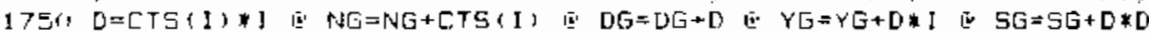

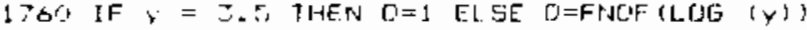

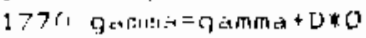

17 (A) HEXT I

1796 FOF $I=N J T$ TO NE

180 IT CTS (I) $\Rightarrow 0$ THEN GOTO 1 G60

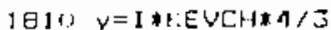

1020 IF I:INT (IIS/VEVCH) THEN RGTD=DN F FSTY=YN

$18 \Xi 0, D=C T S\{I) * I$ I $N N=N N+C T S$ (I) E $D N=D N+D$ I $\quad Y N=Y N+D * I \quad$ E $\quad S N=S N+D * D$

1840 IF $\forall=175$ THEN $Q=20$ ELSE DFFNOF (LDG $(y)$

1851 ) neutron=neutron+D*O

1 Bsi, NEXT I

$1 E 7 C T=L T / Y 600$

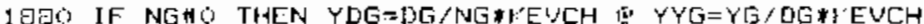

$1890, N T=N G+N N$ Q $D T=D G+D N$ II $Y T=Y G+Y N$

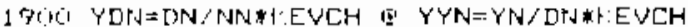

$1910 Y D T=(D G+D N) /(N E+N N) * F=C H E \bar{E} Y Y T=(Y G+Y N) /(D G+D N) * F E V C H$

1920 LEG $=Y Y O \$ B / 9$ IE LEIN=YYN*G,

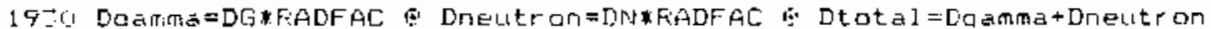

1941 ST=SCF ( $S G+S N)$ *FADFAC E' SG=SCR (SG) *FADFAC İ SN=SQF (SN) *FADFAC

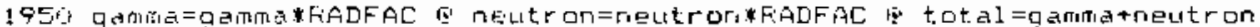

1960 IF DG\#! THEN CFG $=$ a

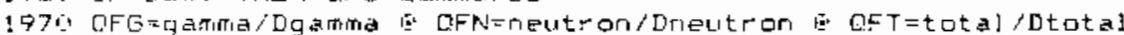

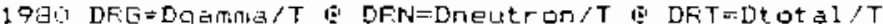

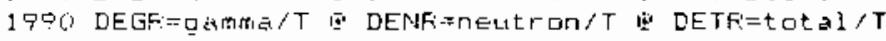

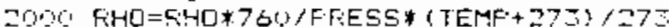

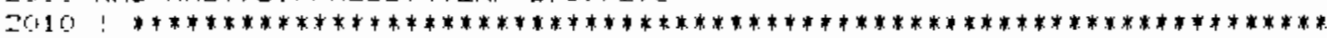

2020: Dutput data to CRT and HF Frinter

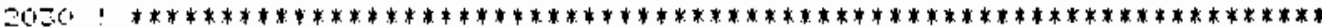

AHO FOF FTE:=2 TO 701 STEF 699

2050 FFINTER IS F.TF:

20G FFINT USING 44J0; "FFOGFAT TEFC" "FAGE "QVAL

Z7O FFINT USING 4440: "VERSIQN MAF, i984". "DATE: "\$D\$, "TIME: "QTIME\$

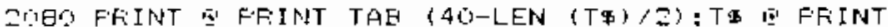

2070 FEINT USING 4450 ; "INFUT FILE NAME: "\$F"

21II FFIMT USING 4AGL; ; "TEFC GUTFUT SUMMAFY"

ZIIO FFINT USING 447\%: "----TEFC OFERATING FAFAMETEFS----"

ZIZC FFINT USING 4480 ; "TE GAS" "TE GAS". "TE GAS". "TE GAS". "TE GAS"."TEMFEFATUF" E" "FFESSUFIE" . "DEMSITY" "MASS"

2130 FFINT USINE 4490 : "(deg-C)". "(torr)" "(g/ce)", "(a)"

$214 C$ FRINT USING $45 \%$ : GAS\$, TEMF, F'FESS. FHO, MASS

2156 FRINT USING 4510 : "CHAMEEF DIAMETEF:" ". DIA." cm". "SITE EQUIVALENT DIAMETEFi

$=$ "EDDIA." microns"

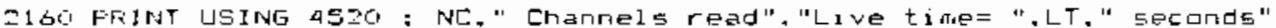

2170 FFINT USING 45.0; ; "Fraton Drop Foint= Chammel "FFF," equlvalent to ". H*FOF., " heVimieran"

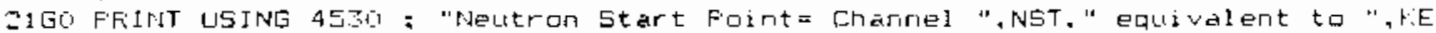
VEHANST." I EW'micran"

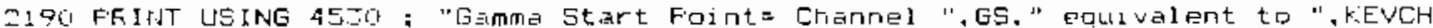
*GS, " heVimicron"

=IOO FRIIT USING 4540; "---DISTFIEUTION FAFIAMETERS----"

ZZ10 FFINT USING 4550 : "aAmina" "neutrori" "total"

ZZZO FRINT USING $4540 ;$ : CoLints/Ch",NG,NN.NT

"न30 FFINT USING 456r: "CoLITE*Ch",DG.DN.DT

Z240 FSIIIT USING 456\%; "CDunts*RhE", YG, YN, YT

235G FEINT LISING 457C ; "Y-LAT F". YDG, YDN. YDT

2.0 FFIIN! USINLG 4570 ; "Y-bar D", YYG, YYN, YYT

$2 Z 70$ FFINT USING 4570 ; "L-bar D".LFG,LEN, LET

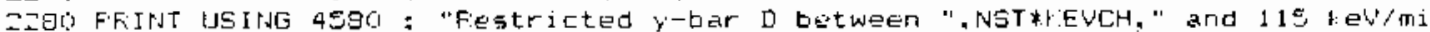




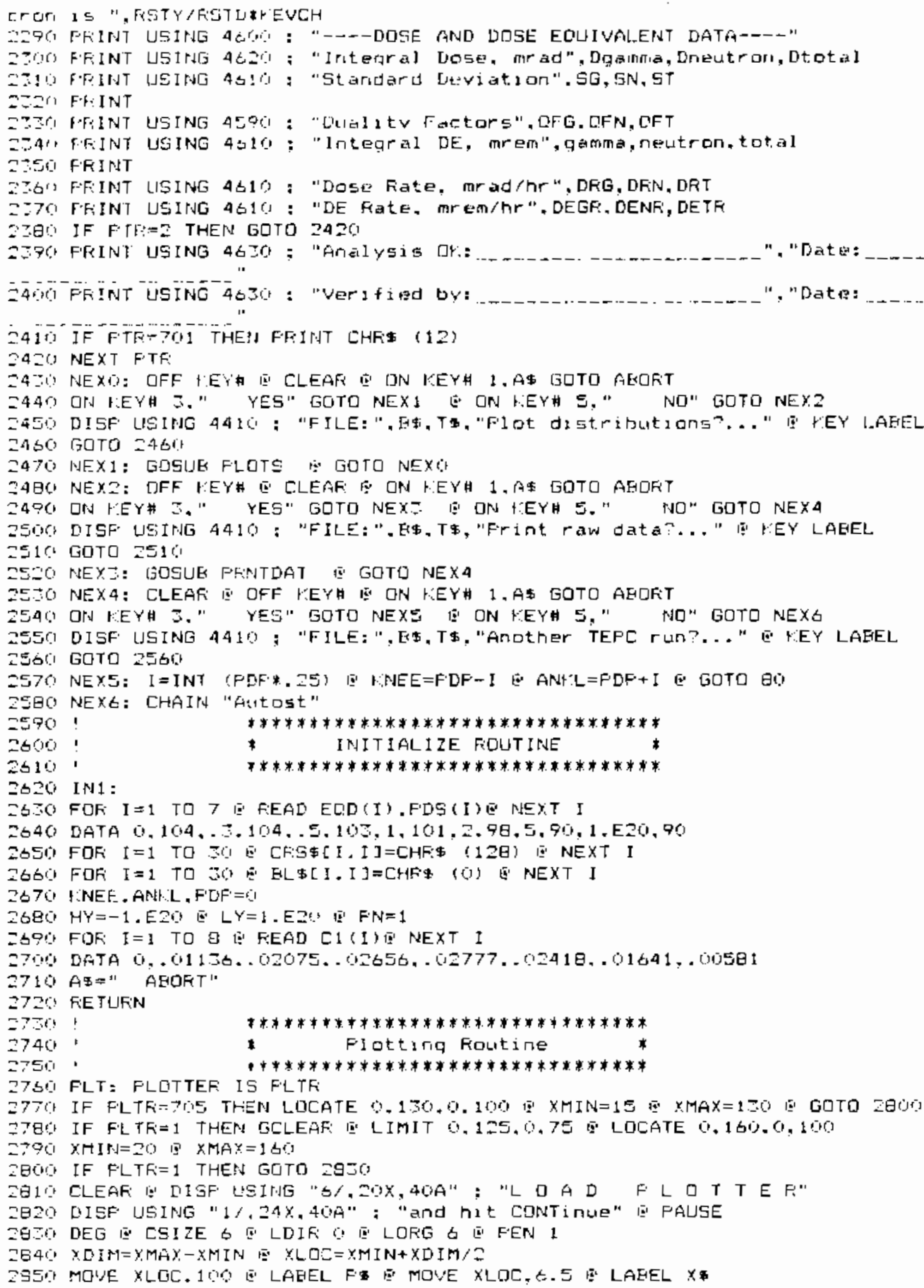




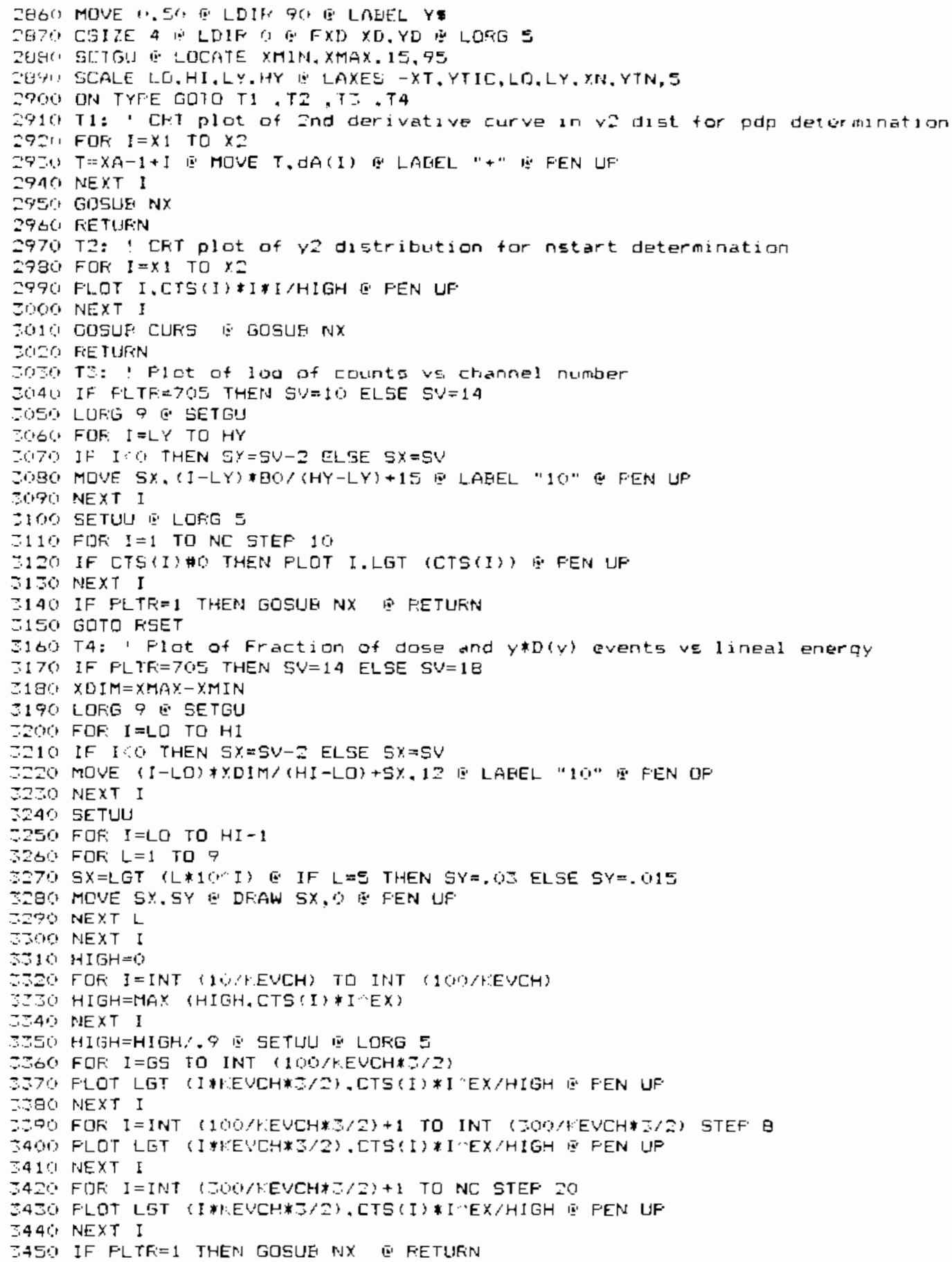




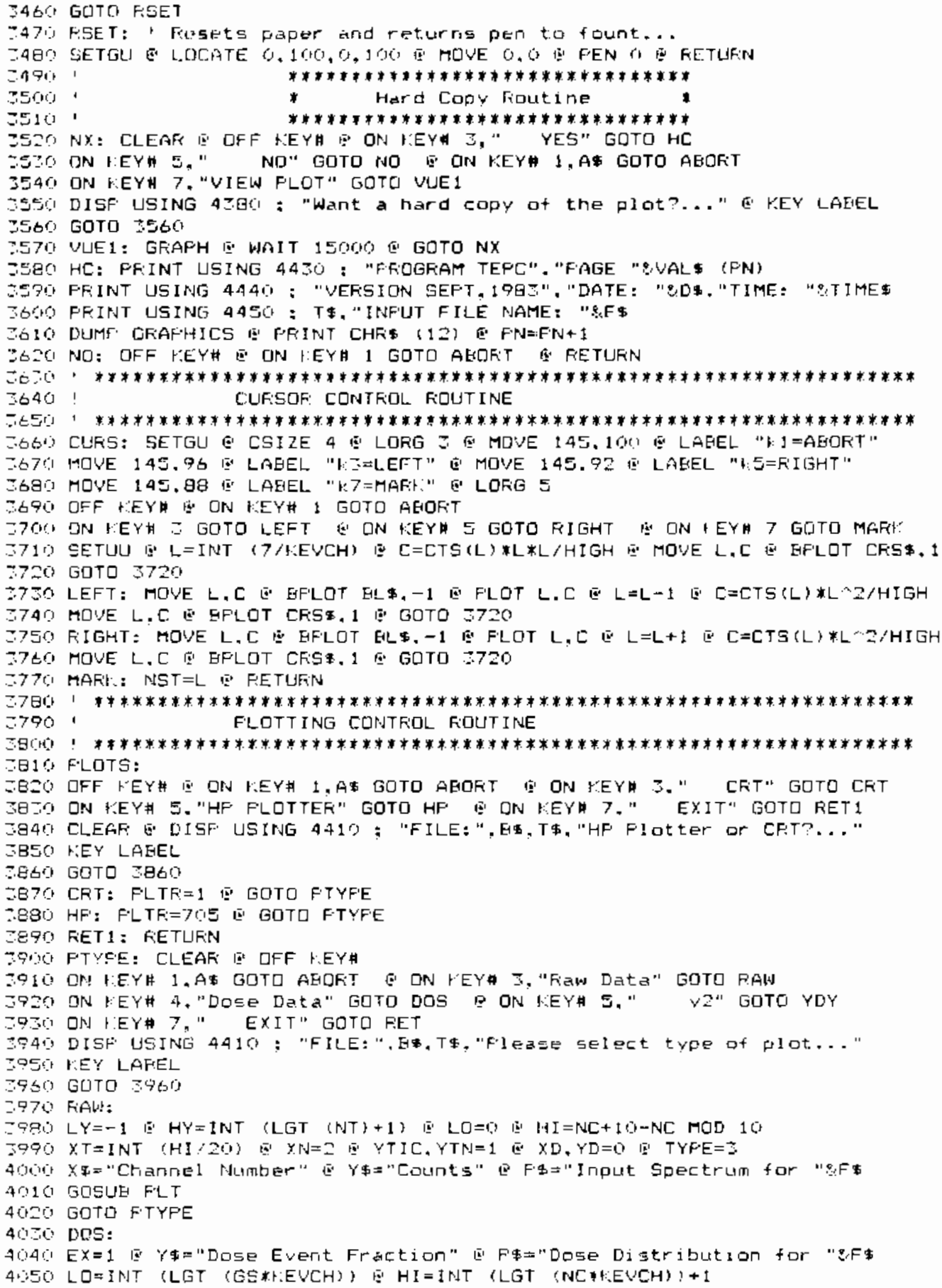




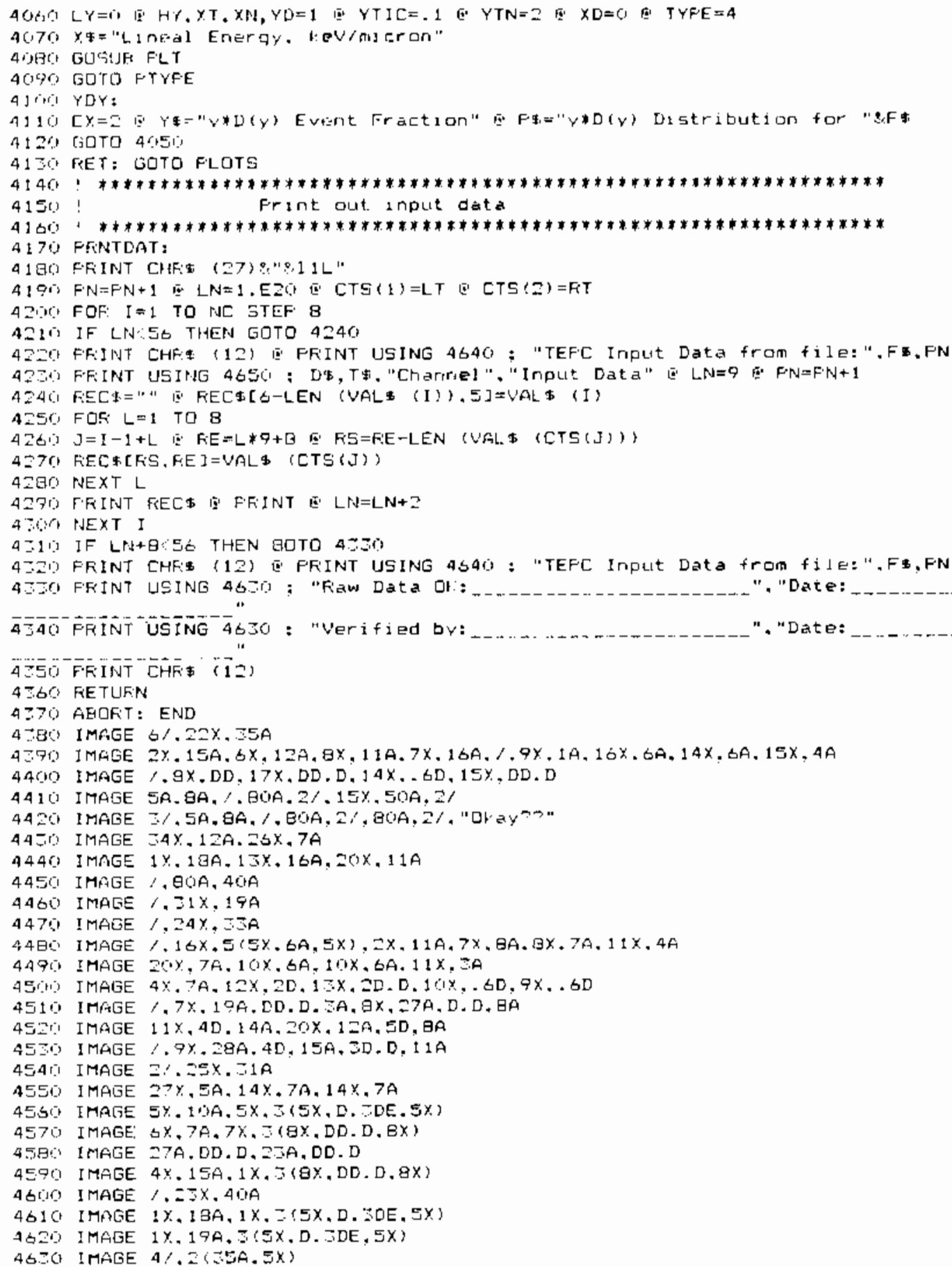


4Q4C IMAGE $21 \times, 264.2 x$. BA, 16X, "FAGE ", 1 X, 2D

4G5U IMAGE $35 X, 104,2 / .6 O A, 3 \%, 7 A, 22 X, 10 A, 2 /$

46 a.. [ND

A. 9 
. 
APPENDIX B

GLOSSARY OF VARIABLES 


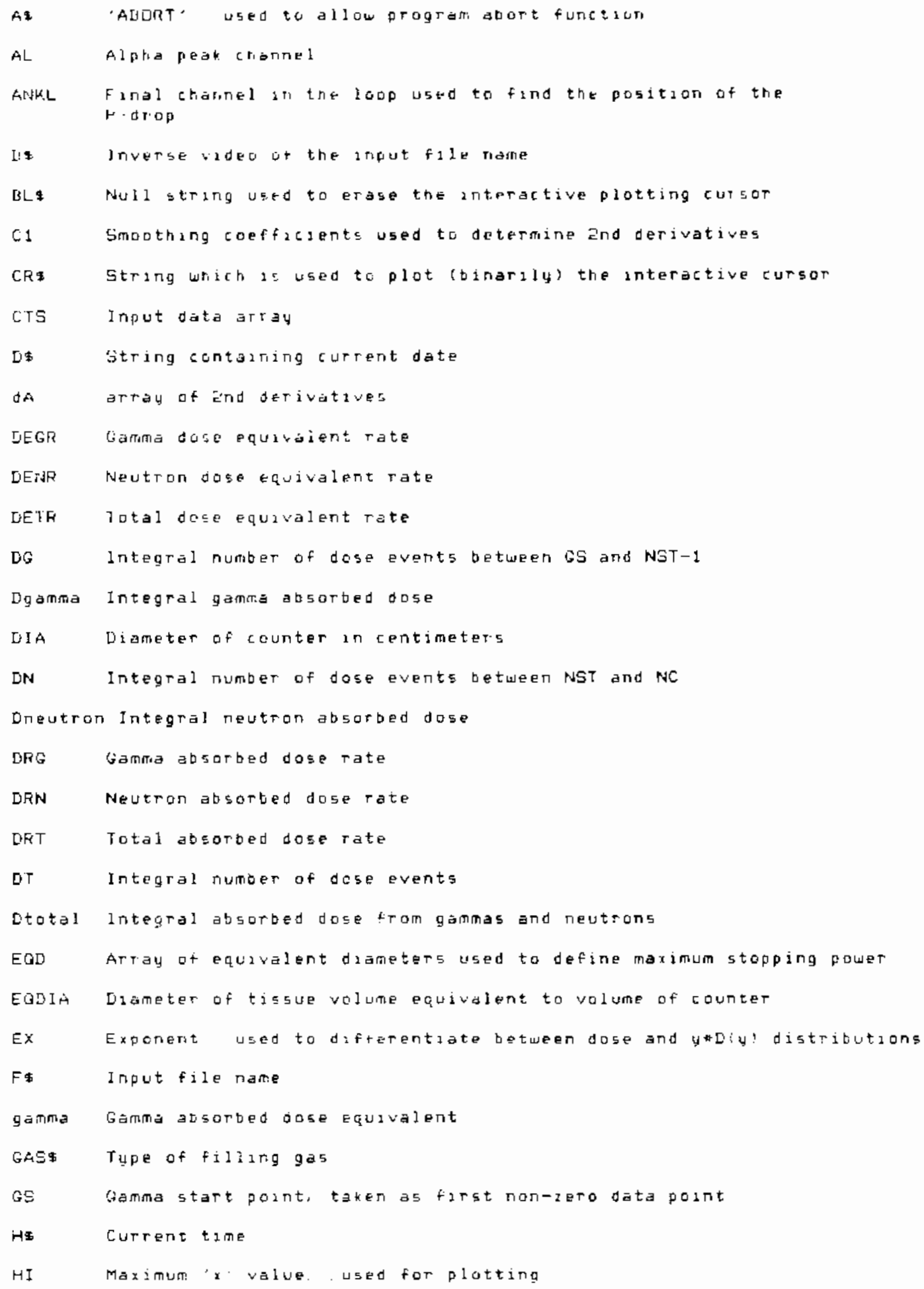




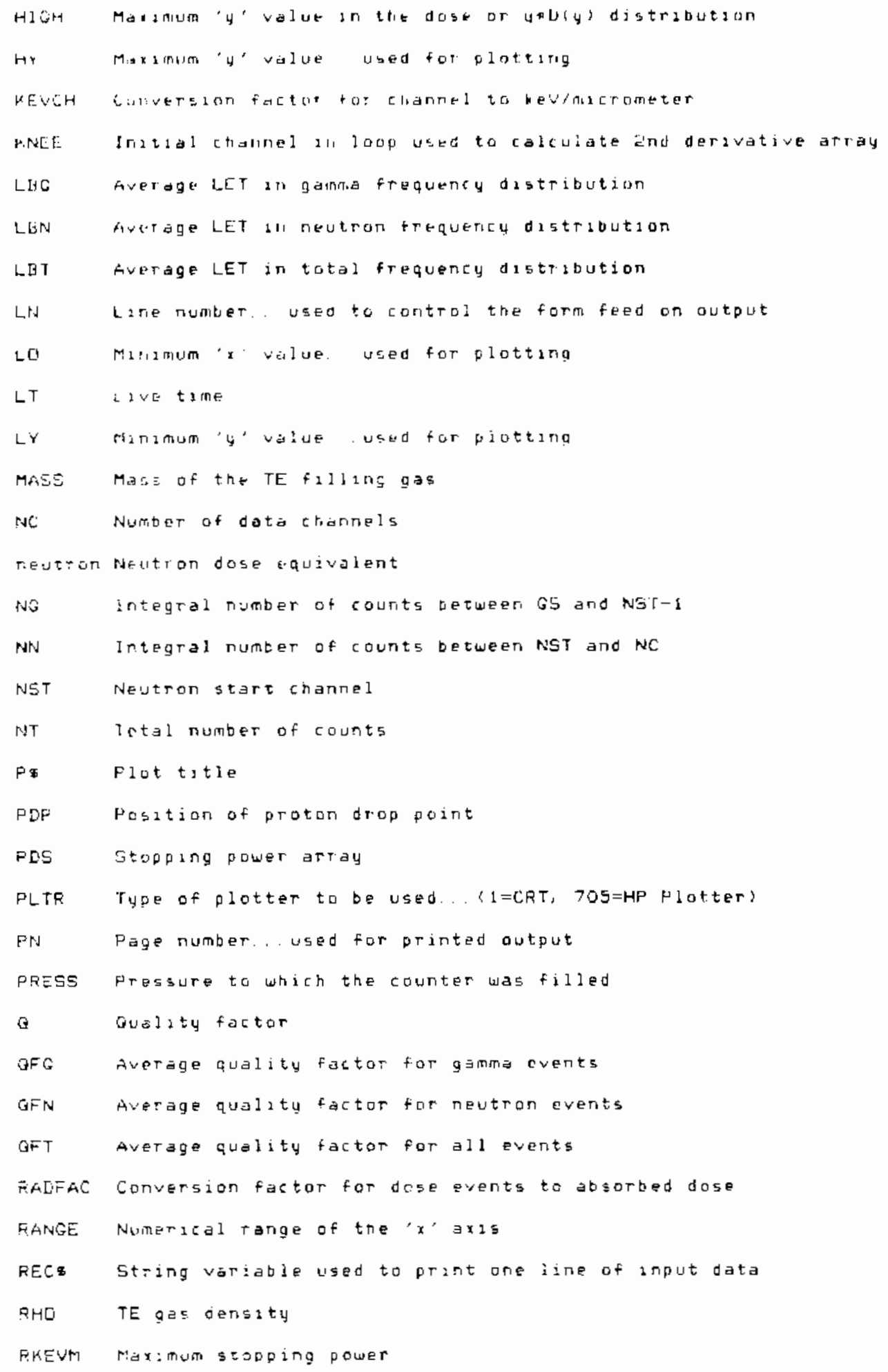




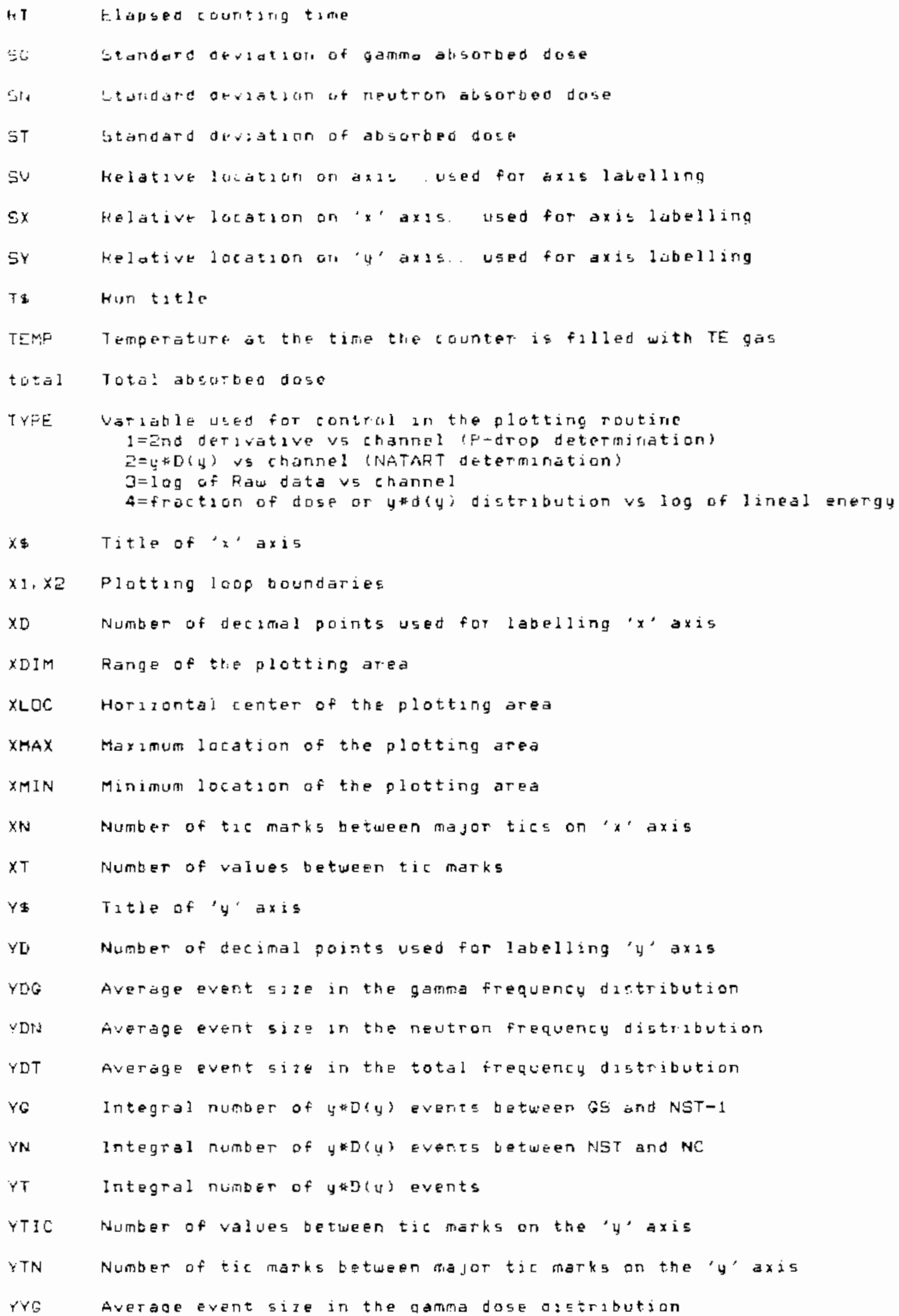


YYN Average event 5 ale in the reutron dase dastrabution

Pyt Avetagt puert $52 z$ ar the dosp distritution 


\section{APPENDIX C}

GLOSSARY OF SUBROUTINES 


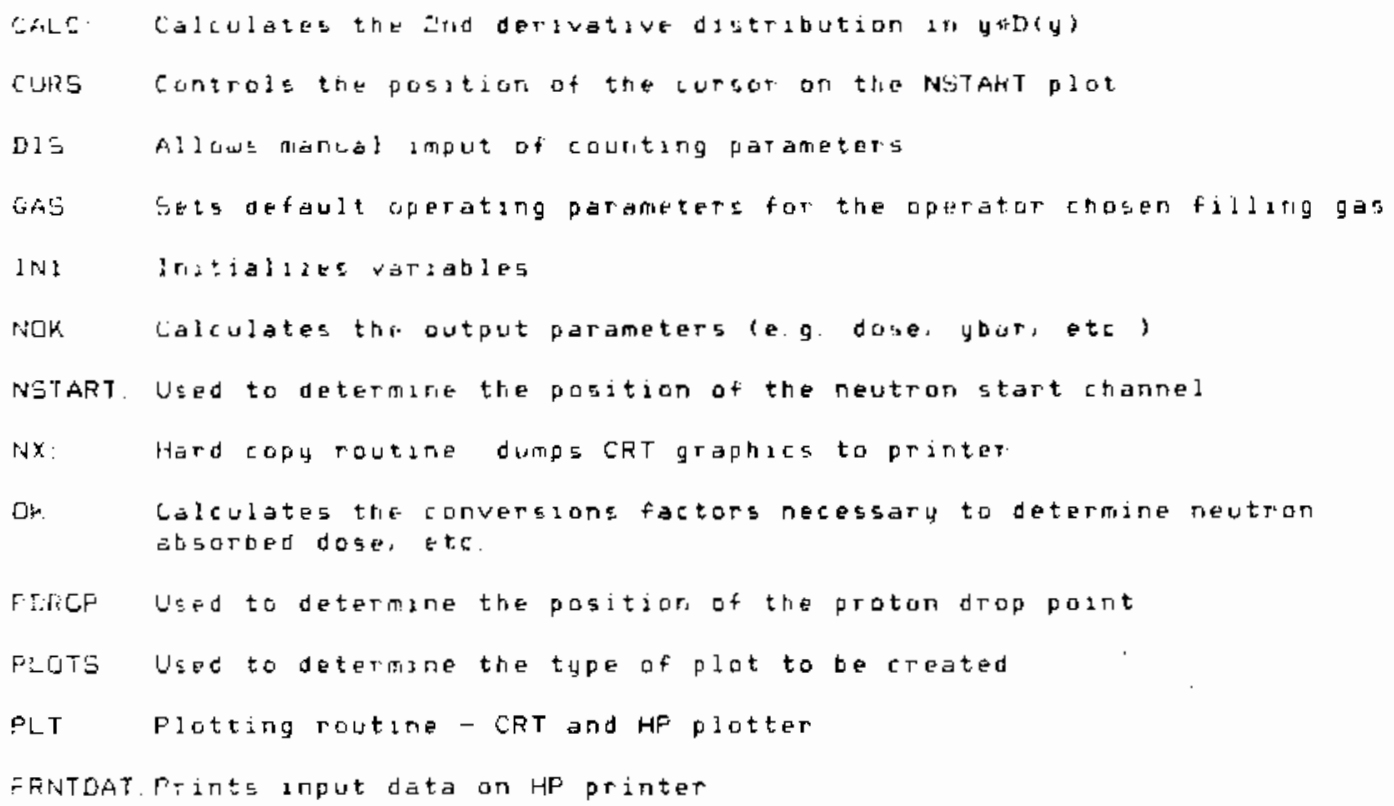




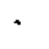

. 
APPENDIX D

BENCHMARK MEASUREMENT 


\section{VEFSION SEFT. 198:}

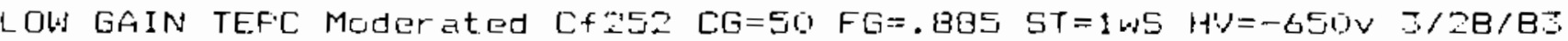
INFUT FILE NAME: NESB

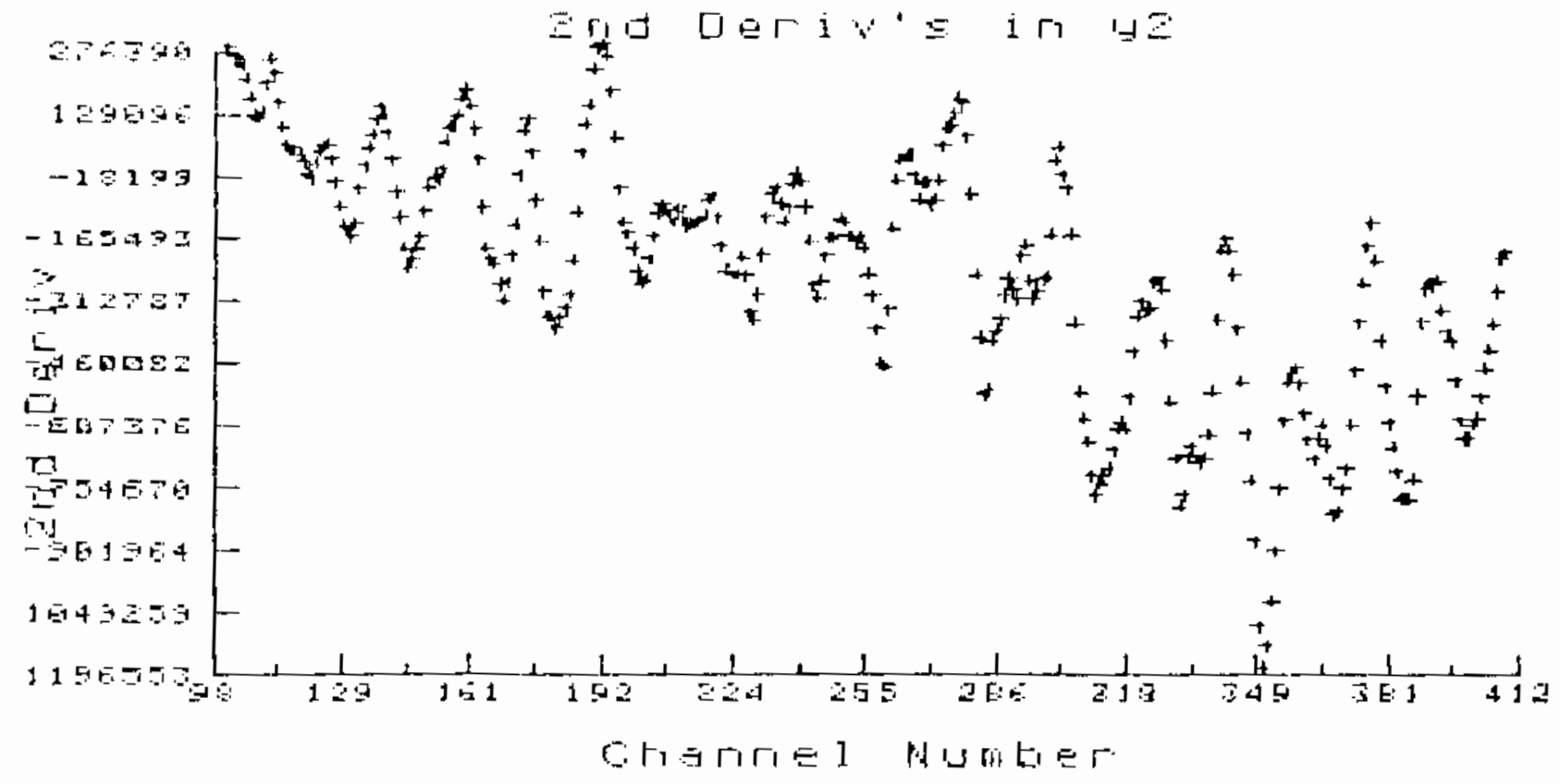




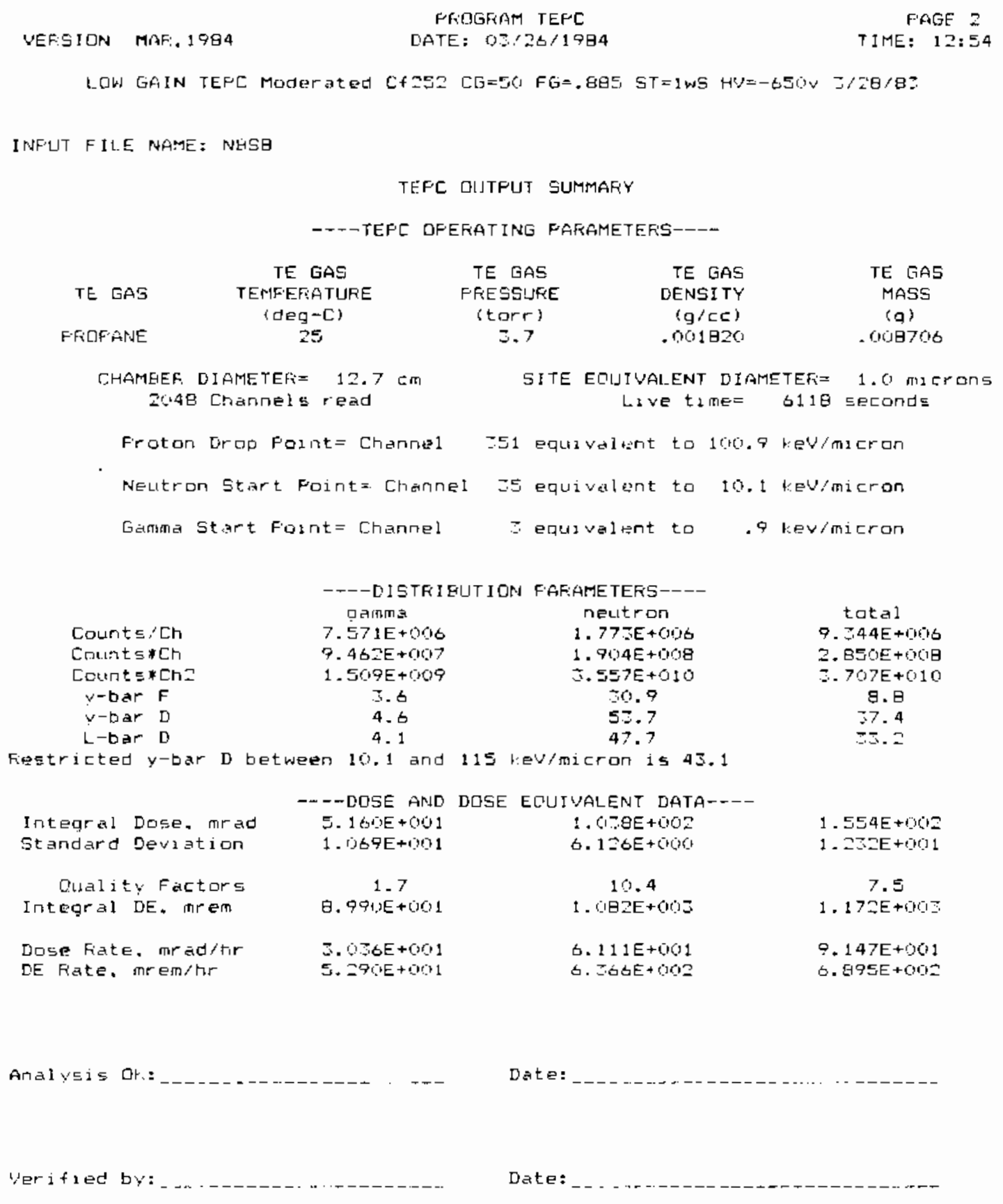




\section{VEF:SION SEF'T, $198:$}

FFOGFAM TEF'C

DATE: $0, / 26 / 1984$

FAGE :

LOW GAIN TEFC Moderated Cf 252 CG $=50 \mathrm{FG}=.685 \mathrm{ST}=1$ w5 HV=-650V $5 / 28 / 83$ INFUT FILE NAME: NESE

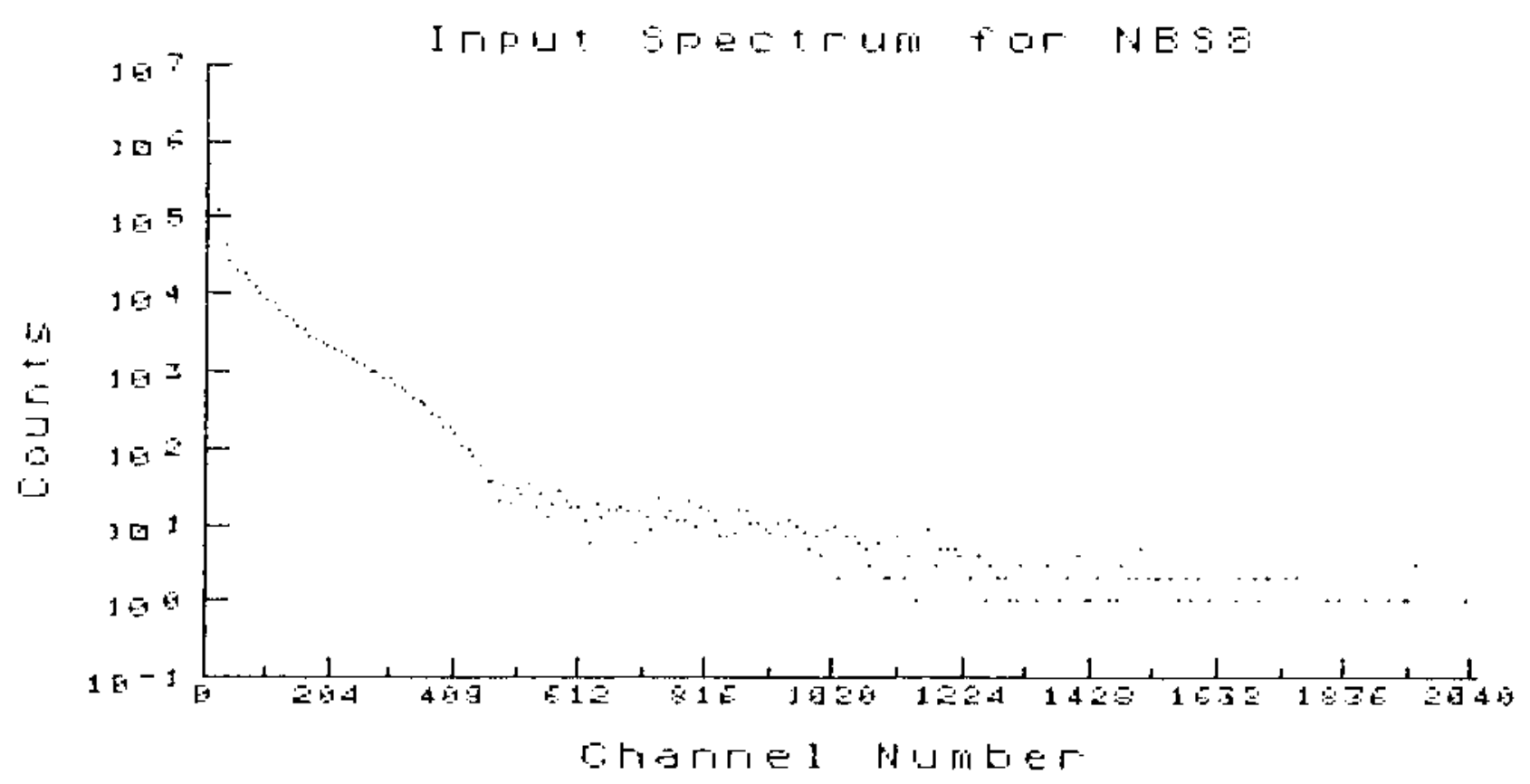


LOW GAIN TEFC Moder ated CF 252 CG $=50$ FG $=.985 \quad 5 T=1$ wS $H V=-650 \mathrm{~V} \quad 5 / 28 / 63$ INFLIT FILE NAME: NBSG

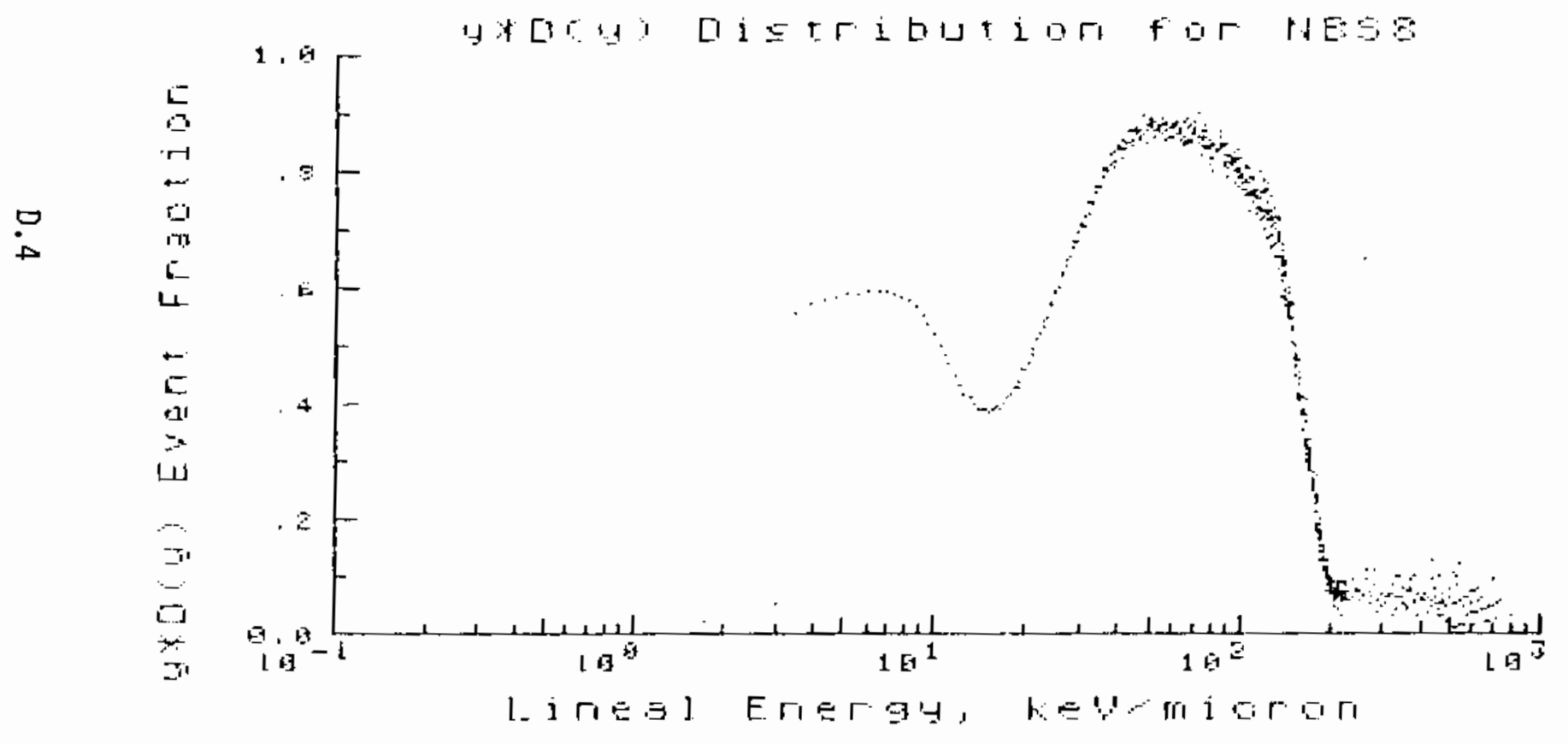


DISTRIBUTION

No. of

Copies

\section{OFFSITE}

E. J. Vallario

Division of Operational Safety

Department of Energy

Washington, DC 20545

27 DOE Technical Information Service

R. B. Schwartz

U.S. National Bureau of Standards

Quince Orchard Rd.

Gaithersburg, MD 20760

ONS ITE

DOE Richland Operations Office

H. E. Ransom/P. K. Clark
No. of

Copies

38 Pacific Northwest Laboratory

L. W. Brackenbush

F. M. Cummings (10)

G. W. R. Endres

L. G. Faust

R. T. Hadley

D. E. Hadlock (5)

D. L. Haggard

G. R. Hoenes

J. C. McDonald

J. L. Pappin

W. R. Reece

P. L. Roberson

R. I. Scherpelz

J. M. Selby

K. L. Soldat

K. L. Swinth

J. E. Tanner

P. L. Tomeraasen

Technical Information (5)

Publishing Coordination (2) 
